\title{
The De-Icing Comparison Experiment (D-ICE): a study of broadband radiometric measurements under icing conditions in the Arctic
}

\author{
Christopher J. Cox ${ }^{1}$, Sara M. Morris ${ }^{1}$, Taneil Uttal ${ }^{1}$, Ross Burgener ${ }^{2}$, Emiel Hall ${ }^{2,3,4}$, Mark Kutchenreiter ${ }^{5}$, \\ Allison McComiskey ${ }^{6}$, Charles N. Long ${ }^{2,3,4,}$, Bryan D. Thomas $^{2}$, and James Wendell ${ }^{2}$ \\ ${ }^{1}$ NOAA Physical Sciences Laboratory (PSL), Boulder, Colorado, 80305, USA \\ ${ }^{2}$ NOAA Global Monitoring Laboratory (GML), Boulder, Colorado, 80305, USA \\ ${ }^{3}$ Cooperative Institute for Research in Environmental Sciences (CIRES), Boulder, Colorado, 80305, USA \\ ${ }^{4}$ University of Colorado, Boulder, Colorado, 80305, USA \\ ${ }^{5}$ National Renewable Energy Laboratory (NREL), Golden, Colorado, 80401, USA \\ ${ }^{6}$ Brookhaven National Laboratory (BNL), Upton, New York, 11973, USA \\ $\mathbf{t}_{\text {deceased }}$
}

Correspondence: Christopher J. Cox (christopher.j.cox@ noaa.gov)

Received: 30 September 2020 - Discussion started: 20 October 2020

Revised: 28 December 2020 - Accepted: 4 January 2021 - Published: 16 February 2021

\begin{abstract}
Surface-based measurements of broadband shortwave (solar) and longwave (infrared) radiative fluxes using thermopile radiometers are made regularly around the globe for scientific and operational environmental monitoring. The occurrence of ice on sensor windows in cold environments - whether snow, rime, or frost - is a common problem that is difficult to prevent as well as difficult to correct in post-processing. The Baseline Surface Radiation Network (BSRN) community recognizes radiometer icing as a major outstanding measurement uncertainty. Towards constraining this uncertainty, the De-Icing Comparison Experiment (DICE) was carried out at the NOAA Atmospheric Baseline Observatory in Utqiagivik (formerly Barrow), Alaska, from August 2017 to July 2018. The purpose of D-ICE was to evaluate existing ventilation and heating technologies developed to mitigate radiometer icing. D-ICE consisted of 20 pyranometers and 5 pyrgeometers operating in various ventilator housings alongside operational systems that are part of NOAA's Barrow BSRN station and the US Department of Energy Atmospheric Radiation Measurement (ARM) program North Slope of Alaska and Oliktok Point observatories. To detect icing, radiometers were monitored continuously using cameras, with a total of more than 1 million images of radiometer domes archived. Ventilator and ventilator-heater
\end{abstract}

performance overall was skillful with the average of the systems mitigating ice formation $77 \%$ (many $>90 \%$ ) of the time during which icing conditions were present. Ventilators without heating elements were also effective and capable of providing heat through roughly equal contributions of waste energy from the ventilator fan and adiabatic heating downstream of the fan. This provided $\sim 0.6{ }^{\circ} \mathrm{C}$ of warming, enough to subsaturate the air up to a relative humidity (with respect to ice) of $\sim 105 \%$. Because the mitigation technologies performed well, a near complete record of verified icefree radiometric fluxes was assembled for the duration of the campaign. This well-characterized data set is suitable for model evaluation, in particular for the Year of Polar Prediction (YOPP) first Special Observing Period (SOP1). We used the data set to calculate short- and long-term biases in iced sensors, finding that biases can be up to $+60 \mathrm{~W} \mathrm{~m}^{-2}$ (longwave) and -211 to $+188 \mathrm{~W} \mathrm{~m}^{-2}$ (shortwave). However, because of the frequency of icing, mitigation of ice by ventilators, cloud conditions, and the timing of icing relative to available sunlight, the biases in the monthly means were generally less than the aggregate uncertainty attributed to other conventional sources in both the shortwave and longwave. 
Copyright statement. The US Government retains and the publisher, by accepting the article for publication, acknowledges that the US Government retains a nonexclusive, paid-up, irrevocable, worldwide license to publish or reproduce the published form of this work, or allow others to do so, for US Government purposes.

\section{Introduction}

Radiative fluxes are fundamental environmental observations made regularly from the earth's surface using thermopile radiometers. In cold climates, ice from vapor deposition (frost), contact freezing of supercooled droplets (rime) and accumulation of snow are all commonly observed by station personnel to obscure sensors, and manual cleaning of sensor domes is a routine activity. Icing is the source of one of the least constrained outstanding uncertainties in broadband radiometry in cold climates. For radiometers mounted facing upwards, ice generally increases the measured longwave downwelling (LWD) flux because the brightness temperature of the contaminating ice is typically larger than that of the sky. The relatively cold background of the sky also facilitates radiative cooling of the sensor window, which exacerbates icing relative to instruments pointed towards the ground. Biases can be both negative or positive in affected shortwave downwelling (SWD) fluxes by attenuation or scattering of incident light, respectively. The magnitude of the instantaneous errors has been reported to be up to $80 \mathrm{~W} \mathrm{~m}^{-2}$ in LWD (Persson et al., 2018) and more than $100 \mathrm{~W} \mathrm{~m}^{-2}$ in SWD (van den Broeke et al., 2004; Matsui et al., 2012). Despite these large biases, post-processing of data is hampered by the fact that the signal from data contaminated by ice is difficult to distinguish from the signal caused by clouds. This is particularly problematic for LWD (Lanconelli et al., 2011). Since icing occurs under specific meteorological conditions, even if affected data are successfully removed, the lost data constitute a climatological bias in the record. Therefore, the standard procedure of daily cleaning (McArthur, 2005) is insufficient and it is sometimes necessary to fill data gaps caused by icing with surrogate values (e.g., Persson et al., 2018). It is desirable to identify a solution that prevents the formation of ice in the first place as well as to quantify the biases in contaminated measurements to advance the interpretation of data already collected.

Recognition of the problem and mitigation attempts have been reported since the earliest era of polar radiometric observations more than five decades ago (e.g., Koerner et al., 1963). Since then, engineering solutions have been pursued by research institutes and industry, largely independently and in parallel. In practice, because the nature of the measurement is sensitive to thermal instabilities within the instruments (e.g., Michalsky et al., 2017), the application of heat as an ice-mitigation technique has limitations. While progress has been made, to this day there is still no agreed-upon approach. The needs of the scientific community also increas- ingly require high-quality measurements from stations capable of being autonomous for weeks or months at a time. Thus, an automated, low-power solution to the icing problem is sorely needed.

The Baseline Surface Radiation Network (BSRN) (Ohmura et al., 1998; Driemel et al., 2018), under the auspices of the World Meteorological Organization (WMO), is a global network for surface-based radiometric observations; the BSRN is traceable to the world calibration standard, managed using commonly adopted practices and strategically distributed for global coverage. There are six current and former BSRN stations in the Arctic, three in Antarctica and numerous stations at lower latitudes that are located at high elevations and/or experience icing conditions seasonally. In 2008, BSRN established the Cold Climates Issues Working Group (CCIWG) to address uncertainties in cold regions, including icing (Lanconelli et al., 2011). Several BSRN stations affected by icing have reported increased data capture rates using ventilators, including the Sonnblick station in the Austrian Alps (Weisser, 2016) and the Georg von Neumayer station in Antarctica (BSRN, 2016). The US Department of Energy (DoE) Atmospheric Radiation Measurement (ARM) program North Slope of Alaska Radiometer Campaign also reported that high-flow ventilation was a useful technique, but that ice mitigation was further improved when the air was also heated (BSRN, 2012). A consensus in BSRN thus emerged that heating and ventilation are capable of mitigating ice, but the effectiveness and uncertainties remained poorly quantified, and the range of experiences reported by BSRN users indicated that more work was needed to constrain the attributes of effective designs (BSRN, 2016).

To address these objectives, the NOAA Physical Sciences Laboratory (PSL) in partnership with the BSRN-CCIWG and NOAA Global Monitoring Laboratory (GML) carried out the De-Icing Comparison Experiment (D-ICE) to collect data suitable for assessing the influence of icing on the measurements and evaluating the status of ice-mitigation technology. D-ICE was deployed at the GML Barrow Atmospheric Baseline Observatory near Utqiagivik, Alaska, from August 2017 through June 2018. This location was chosen because a variety of icing conditions characteristic of high latitudes regularly occur there and it is home to two long-term operational stations, one from BSRN (NOAA-GML) the other from DoE-ARM. D-ICE collected new data at the NOAA observatory using a variety of radiometers and housings that have been developed to mitigate the formation of ice or are used in icing environments. The systems were contributed by academic and government research institutions as well as development departments of commercial radiometer vendors and were installed alongside the existing operational suites. The systems were monitored continuously using cameras for the duration of the campaign.

In this paper, we describe D-ICE and associated data sets, which are available for future analyses. These data sets include a $10-15 \mathrm{~min}$ resolution classification of the icing status 
of instruments, quality-controlled versions of the radiometric data with occurrences of icing retained and rejected (Cox, 2020a), and a verified ice-free "best-estimate" (BE) baseline (Cox, 2020b) for comparison produced by the aggregate of the quality-controlled data. We use these data sets to analyze instantaneous and time-averaged biases caused by ice, to calculate ice-mitigation performance statistics for the participating systems, to discern some of the reasons for successful ice mitigation, and to gather insight for interpretation of ice-contaminated data.

\section{Campaign}

\subsection{Experimental design}

D-ICE solicited contributions of radiometric ice-mitigation systems developed by research institutions and industry manufacturers to be part of the campaign. In total, 26 systems were included: 21 housing pyranometers (measuring "global" (hemispheric diffuse + direct) SWD) and 5 housing pyrgeometers (measuring LWD). In addition to the Utqiagivik BSRN station, D-ICE collaborated with the two other operational stations, the DoE-ARM North Slope of Alaska (NSA) site located at Utqiagivik $150 \mathrm{~m}$ west of the BSRN station, and the DoE-ARM Oliktok Point (OLI) site located $250 \mathrm{~km}$ to the east. Data collected at these stations formed a partner campaign termed the D-ICE ARM Component (DICEXACO, Cox et al., 2019). The operational radiometric stations at the three observatories include global unshaded SWD, shaded LWD, and diffuse (DIF) and direct (DIR) shortwave components using a shaded pyranometer and a pyrheliometer, respectively, mounted to a solar tracker. The focus of DICE was on upward-facing pyrgeometers and pyranometers. Pyrheliometer performance is not considered here, but a separate analysis was completed by DoE-ARM (Stuefer et al., 2019).

The ice-mitigation strategy used by all contributors was some combination of heating and ventilation, in some cases supplied by separate housings in which radiometers were set and in others integrated into the instruments themselves. This consistency in approach is not surprising. Though other methods have been proposed, such as automated alcohol rinses (e.g., Persson and Semmer, 2010), the use of ventilators for controlling ice is pragmatic because ventilation is already regularly used for maintaining thermal homogeneity in the instrument. However, no specific criteria were given to potential contributors, and D-ICE set up each system as instructed. Several sets of redundant housings were used with different radiometers or with only small modifications (see File $\mathrm{S} 1$ in the Supplement). All systems were powered using 12 or 24 VDC except for one 48 VAC heater. All fans were powered by DC, which is less prone to propagation of added uncertainty into the signal (Michalsky et al., 2017), in particular from infrared loss in pyranometers (Dutton et al., 2001).

The instruments were installed on the east end of the GML observatory roof in a single line along a $4.9 \mathrm{~m}$ table positioned perpendicular to the predominant wind direction (Fig. 1a) near the BSRN tracker. The purpose of this orientation was to reduce the possibility of instruments being influenced by heat produced from neighboring systems, taking advantage of dominant easterlies characteristic of the site (e.g., Cox et al., 2012). The table was constructed from aluminum with a top consisting of fiberglass resin to electrically isolate the systems. The BSRN global pyranometer was positioned on this table. Refer to File $\mathrm{S} 1$ for a complete record of system specifications and S2 for a list of modifications made during the course of the campaign. Individual radiometers are referenced in the text by their serial number and the ventilators by their model number. The positions of the systems are displayed in Fig. 1b, labeled with numbers that are referenced where appropriate and cross-referenced in File S1.

D-ICE data were collected using four Campbell Scientific CR1000 data loggers in individual logger boxes; most systems were analog, but data were also logged digitally from seven sensors. Fan speeds and heating current were logged whenever possible. All data were recorded as 1 min averages of $1 \mathrm{~Hz}$ sampling except for the digital systems, which were switched to $0.5 \mathrm{~Hz}$ sampling on 26 October 2017 because lags that occurred in digital communications at temperatures below $-10^{\circ} \mathrm{C}$ caused occasional missed scans. The $1 \mathrm{~min}$ averages of wind speed and direction (Lufft $2 \mathrm{~d}$ sonic), temperature (RTD); and relative humidity (Vaisala HMP155) were also recorded at the north end of the table (Fig. 1b) to document localized meteorological conditions complementary to those recorded routinely by NOAA-GML from a nearby tower.

Before deployment in June 2017, the radiometers were calibrated at the NOAA-GML calibration facility in Boulder, Colorado. Per standard procedures, the calibration data were collected without use of the ventilators but did use the same data acquisition system that was later deployed. The digital systems were also included in this procedure for comparison but were not assigned new calibration coefficients because it is impractical to do so. The pre- and post-campaign calibrations (File S3) were found to be within uncertainty for all instruments. The pre-campaign calibration values determined by NOAA-GML are used in the processing of the final data set.

All systems on the D-ICE table were monitored using three $720 \mathrm{p}$ low-light $(0.1 \mathrm{~lx})$ cameras in heated enclosures. The cameras recorded images every $15 \mathrm{~min}$ and were set up such that each captured approximately one-third of the table. They were installed facing west (away from the predominant wind direction). Two $18 \mathrm{~W}$ LED flood lights were fixed to poles to illuminate the table for the cameras. The lights were automatic and only on during low-light conditions. The cameras were functional and unobscured by ice for $97.6 \%$ of the 

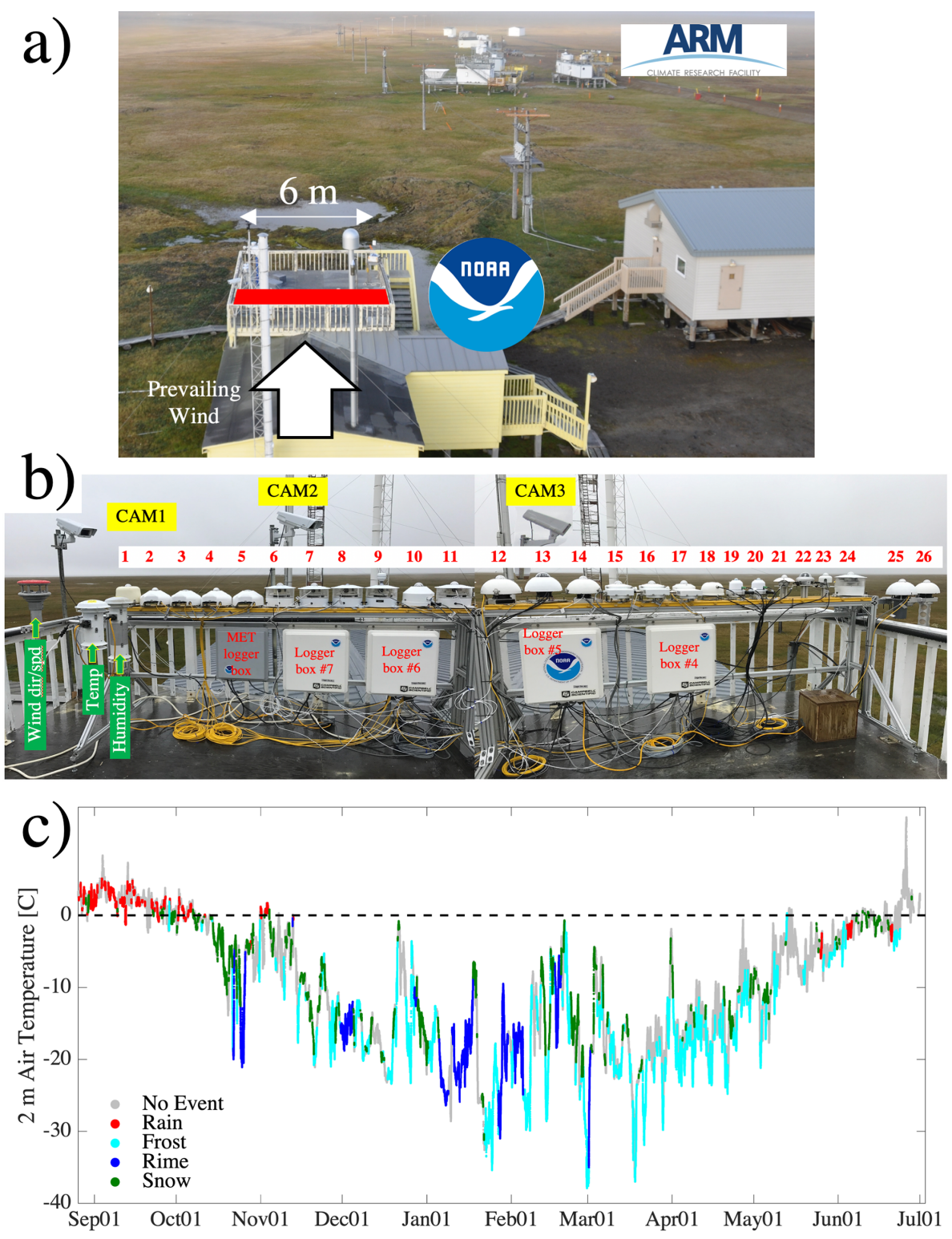

Figure 1. (a) NOAA-GML Barrow Atmospheric Baseline Observatory in Utqiagivik, Alaska (71.325 $\mathrm{N}, 156.625^{\circ} \mathrm{W}, 8 \mathrm{~m}$ a.s.1), DoE-ARM facility in the background (image from https://www.esrl.noaa.gov/gmd/obop/brw/, last access: 24 February 2017). The red square in (a) shows location and orientation of the D-ICE table, which is pictured in (b). (c) Time series of air temperature color-coded with the types of precipitation and icing events that were recorded: rain (red), frost (cyan), rime (blue), snow (green), and no event (grey).

campaign. ARM also installed cameras facing the trackers at OLI and NSA with 10 min sampling.

The BSRN and ARM operational systems received their routine daily maintenance procedures. Daily cleaning was performed to remove contaminants such as dust and salt residues, but also ice. Since one of the objectives of D-ICE was to monitor icing it was important to allow icing events to unfold naturally. Therefore, the D-ICE radiometers were cleaned daily only when there was no ice present. Infrequently, in cases when ice persisted on a particular radiometer long after the end of an event, the ice was removed. These dates were 24 October; 14, 22, 25, and 29 (no. 1) January; 7 February; and 14 and 27 March (no. 10). Interestingly, we found that icing can be induced by the very maintenance procedures that are designed to remove it. The use of alcohol (such as ethanol) to clean the domes is common practice and was documented during tests at D-ICE to sometimes result in immediate re-icing of the dome. The precise reasons for this are not known, but it is likely a combination of refreezing meltwater from the ice that is residual being slower to evaporate than the alcohol, and/or atmospheric vapor deposition induced by cooling of the dome from the evaporative pro- 
cess. Complete drying of the dome after cleaning was found to reduce this problem.

\subsection{Icing conditions during D-ICE}

In this section we characterize the natural icing events that occurred in the environment surrounding the D-ICE systems to set the context for the types and frequency of icing events to which the ice mitigation systems were subjected. During August and September, the temperatures were persistently above freezing with occasional light snow and frequent rain (Fig. 1c). Significant icing was not observed until a prolonged cold period after 22 October, with only brief frosts prior on 28 September and 10 October. Warm temperatures and rain returned during the first week of November and more winter-like conditions prevailed only in the second half of the month. Autumn 2017 experienced record late freezing of the Beaufort and Chukchi seas (Overland and Wang, 2018), with freezing beginning in earnest north of Utqiagivik in late November. Because of the predominant onshore flow at Utqiagivik, autumn temperatures there remain near-freezing until after the sea ice isolates the supply of heat from the ocean (Wendler et al., 2014) and the onset of the snowpack is subsequently delayed in late freeze-up years (Cox et al., 2017). These conditions may have also contributed to the delay in the start of the 2017 icing season.

During the winter, both rime (usually from freezing fog) and frost were regularly observed in the environment surrounding the D-ICE systems (distinguished qualitatively from the images), spanning a total of 28.8 and $66.3 \mathrm{~d}$, respectively. Frost events were more common, being identified 108 times compared to 11 rime events, but the duration of individual rime events was longer. The mean duration of frost events was $0.61( \pm 0.69) \mathrm{d}$ and the mean duration of rime events was $2.6( \pm 2.2)$ d. Diurnal (morning) frosts were commonly observed during spring.

During the campaign, $34.9 \%$ of the time that rime or frost was observed to be present in the vicinity of the D-ICE systems, the station meteorology indicated that the relative humidity with respect to ice (RHI) was $<100 \%$. Note that this calculation is sensitive to the determination of the "end" of an icing event, which in practice was found subjectively using the camera images, and is therefore uncertain (refer to Sect. 2.3.4). Nevertheless, this implies that the portion of time the ice was present and sublimating was approximately one-third of the duration of presence of ice on surfaces surrounding the experiment. This period was longer for frost $(41.6 \%)$ than rime $(14.1 \%)$, which is surprising because riming events were generally observed with a thicker coating of ice than frost, but this may be explained by the fact that rime events were much more persistent than frost. Conversely, $15 \%$ of the time during which no icing was observed the RHI exceeded $100 \%$. Thus, RHI alone was not a reliable proxy for the presence or absence of icing.

\subsection{Data processing}

Here we describe the processing of the data streams, beginning with review and classification of the images in Sect. 2.3.1 and then the radiometric data in Sect. 2.3.2, summarized in Table 1. The processed data streams were then used to produce a BE data set that is the average of the calibrated, bias-corrected, ice-free, and quality-controlled data streams in Sect. 2.2.3, from which uncertainties are derived in Sect. 2.3.4. A second ice-estimate data set was also made that received all of the same treatment except that occurrences of icing were retained for analysis.

\subsubsection{Processing of the D-ICE images}

The images captured approximately 780000 views of the D-ICE radiometer domes with an additional 143000 and 125000 views captured by ARM at NSA and OLI, respectively. Images were captured of the BSRN global pyranometer and all 25 D-ICE radiometers, but not the instruments mounted on the BSRN tracker. At NSA and OLI, images of the global SWD, DIF, and LWD tracker radiometers were captured, but only limited images of the pyrheliometers were made (see Stuefer et al., 2019). The status of each dome in each image was recorded in a spreadsheet after manual review. Because of the large volume of images, this was done in movie form in 1-month intervals, one radiometer at a time. The radiometer domes were classified as being wet (e.g., raindrops or melted ice and slush); containing frost, rime, or snow accumulation; having accumulation of snow around the domes (but not on the domes); being wet with ethanol (used for cleaning); and (rarely) having "other" contaminants, such as resting birds. Occurrences of rime and frost always took precedence in the classification. For example, in cases when snow and rime simultaneously affected a radiometer, the status of the instrument was recorded as rimed. Note that because the domes are hemispheric, the cameras were blind to some parts of the domes, though this was somewhat alleviated by the fact that the pyranometer domes are transparent and the pyrgeometer domes are relatively small and/or flat. All visible ice regardless of amount or coverage was recorded. Thus, the classification was conservative; a snowflake or thick coating of rime were both flagged as iced. Camera downtime was also indicated.

To increase the robustness of the icing determinations, additional instances of ice were identified by comparing each of the data streams to the average of all the data streams and reviewing the images where anomalies were found. While this procedure successfully identified instances of icing that had been missed, the number of identifications increased by $<0.5 \%$. This indicates that the original classification was sufficient to identify the icing that impacted data quality. However, the statistics compiled for the presence of ice include occurrences that were too minor to bias the measured signal and these occurrences were also common and their 
Table 1. List of quality control procedures received by D-ICE instruments. An "X" denotes that the procedure was implemented and "O" indicates that the procedure was not implemented.

\begin{tabular}{|c|c|c|c|c|c|c|c|c|c|c|}
\hline $\begin{array}{l}\text { Table } \\
\text { position }\end{array}$ & $\begin{array}{c}\text { Radiometer } \\
\text { serial no. }\end{array}$ & Band & $\begin{array}{l}\text { Calibration } \\
\text { source }\end{array}$ & $\begin{array}{c}\text { Table } \\
\text { illumination } \\
\text { Removed }\end{array}$ & $\begin{array}{l}\text { QC: visual } \\
\text { screening }\end{array}$ & $\begin{array}{l}\text { QC: long } \\
\text { and Shi } \\
(2008)\end{array}$ & $\begin{array}{c}\text { QC: } \\
\text { shadow flag }\end{array}$ & $\begin{array}{l}\text { QC: icing } \\
\quad \text { flag }\end{array}$ & $\begin{array}{l}\text { QC: IR-loss } \\
\text { correction }\end{array}$ & QC notes \\
\hline 1 & $34231 \mathrm{~F} 3$ & SW & GMD & $\mathrm{X}$ & $\mathrm{X}$ & $\mathrm{X}$ & $\mathrm{X}$ & $\mathrm{X}$ & $\mathrm{X}$ & None \\
\hline 2 & 160478 & SW & GMD & $X$ & $\mathrm{X}$ & $\mathrm{X}$ & $\mathrm{X}$ & $\mathrm{X}$ & $\mathrm{X}$ & None \\
\hline 3 & 160183 & LW & GMD & $\mathrm{O}$ & $\mathrm{X}$ & $\mathrm{X}$ & $\mathrm{O}$ & $\mathrm{X}$ & $\mathrm{O}$ & None \\
\hline 4 & 160002 & SW & Factory & $X$ & $\mathrm{X}$ & $\mathrm{X}$ & $\mathrm{X}$ & $X$ & $\mathrm{O}$ & None \\
\hline 5 & 160008 & LW & Factory & $\mathrm{O}$ & $\mathrm{X}$ & $\mathrm{X}$ & $\mathrm{O}$ & $\mathrm{X}$ & $\mathrm{O}$ & None \\
\hline 6 & $26818 \mathrm{~F} 3$ & SW & GMD & $\mathrm{X}$ & $\mathrm{X}$ & $\mathrm{X}$ & $\mathrm{X}$ & $\mathrm{X}$ & $\mathrm{X}$ & None \\
\hline 7 & $18135 \mathrm{~F} 3$ & SW & GMD & $X$ & $\mathrm{X}$ & $\mathrm{X}$ & $\mathrm{X}$ & $X$ & $\mathrm{X}$ & None \\
\hline 8 & $34309 \mathrm{~F} 3$ & LW & GMD & $\mathrm{O}$ & $X$ & $\mathrm{X}$ & $\mathrm{O}$ & $\mathrm{X}$ & $\mathrm{O}$ & None \\
\hline 9 & $28507 \mathrm{~F} 3$ & LW & GMD & $\mathrm{O}$ & $\mathrm{X}$ & $\mathrm{X}$ & $\mathrm{O}$ & $\mathrm{X}$ & $\mathrm{O}$ & None \\
\hline 10 & F16305R & SW & GMD & $X$ & $\mathrm{X}$ & $\mathrm{X}$ & $\mathrm{X}$ & $X$ & $\mathrm{X}$ & None \\
\hline 11 & 26214 & SW & GMD & $X$ & $\mathrm{X}$ & $\mathrm{X}$ & $\mathrm{X}$ & $X$ & $\mathrm{X}$ & No cleaning; poor level \\
\hline 12 & 130814 & SW & GMD & $\mathrm{X}$ & $\mathrm{X}$ & $\mathrm{X}$ & $\mathrm{X}$ & $\mathrm{X}$ & $\mathrm{X}$ & Fan dead 27 Dec 2017 to 4 Jan 2018 \\
\hline 13 & A1571 & SW & Factory & $X$ & $\mathrm{X}$ & $\mathrm{X}$ & $\mathrm{X}$ & $\mathrm{X}$ & $\mathrm{O}$ & Ventilator shadowing \\
\hline 14 & $20523 \mathrm{~F} 3$ & SW & GMD & $\mathrm{X}$ & $\mathrm{X}$ & $\mathrm{X}$ & $\mathrm{X}$ & $\mathrm{X}$ & $\mathrm{X}$ & Fan dead 19 Jan 2018 to 8 Feb 2018 \\
\hline 15 & $38172 \mathrm{~F} 3$ & SW & GMD & $\mathrm{X}$ & $\mathrm{X}$ & $\mathrm{X}$ & $\mathrm{X}$ & $\mathrm{X}$ & $\mathrm{X}$ & None \\
\hline 16 & 26236 & SW & GMD & $\mathrm{X}$ & $\mathrm{X}$ & $\mathrm{X}$ & $\mathrm{X}$ & $\mathrm{X}$ & $\mathrm{X}$ & None \\
\hline 17 & 130819 & SW & GMD & $\mathrm{X}$ & $\mathrm{X}$ & $\mathrm{X}$ & $\mathrm{X}$ & $\mathrm{X}$ & $\mathrm{O}$ & None \\
\hline 18 & 4037 & LW & Factory & $\mathrm{O}$ & $\mathrm{X}$ & $\mathrm{X}$ & $\mathrm{O}$ & $\mathrm{X}$ & $\mathrm{O}$ & None \\
\hline 19 & S16088025 & SW & GMD & $\mathrm{X}$ & $\mathrm{X}$ & $\mathrm{X}$ & $\mathrm{X}$ & $\mathrm{X}$ & $\mathrm{O}$ & None \\
\hline 20 & S16090016 & SW & GMD & $\mathrm{X}$ & $\mathrm{X}$ & $\mathrm{X}$ & $\mathrm{X}$ & $\mathrm{X}$ & $\mathrm{O}$ & None \\
\hline 21 & 2510 & SW & GMD & $\mathrm{X}$ & $\mathrm{X}$ & $\mathrm{X}$ & $\mathrm{X}$ & $\mathrm{X}$ & $\mathrm{O}$ & None \\
\hline 22 & A1338 & SW & Factory & $\mathrm{X}$ & $\mathrm{X}$ & $\mathrm{X}$ & $\mathrm{X}$ & $\mathrm{X}$ & $\mathrm{O}$ & None \\
\hline 23 & 2060 & SW & Factory & $X$ & $\mathrm{X}$ & $\mathrm{X}$ & $\mathrm{X}$ & $\mathrm{X}$ & $\mathrm{O}$ & None \\
\hline 24 & 8041 & SW & GMD & $\mathrm{X}$ & $\mathrm{X}$ & $\mathrm{X}$ & $\mathrm{X}$ & $\mathrm{X}$ & $\mathrm{O}$ & None \\
\hline 25 & 130617 & SW & GMD & $\mathrm{X}$ & $\mathrm{X}$ & $\mathrm{X}$ & $\mathrm{X}$ & $\mathrm{X}$ & $\mathrm{O}$ & None \\
\hline 26 & 970426 & SW & GMD & $\mathrm{X}$ & $\mathrm{X}$ & $\mathrm{X}$ & $\mathrm{X}$ & $\mathrm{X}$ & $\mathrm{X}$ & None \\
\hline
\end{tabular}

identification subject to qualitative interpretation. The relevance of this limitation is discussed further in Sect. 4.1 where the statistics are reported.

\subsubsection{Baseline data from the trackers}

While the BSRN instruments that were mounted on the solar tracker were not imaged by the cameras, the tracker instruments provide important information for two reasons: first, the pyrgeometers were shaded, which reduces solar heating of the domes (Alados-Arboledas et al., 1988) and the magnitude of associated corrections that apply to some pyrgeometers (Albrecht and Cox, 1977), and second, because SWD is more accurately represented by the sum (hereafter, "SUM") of the DIF and DIR due to increased calibration uncertainty in pyranometers from the direct beam at low sun angles (Michalsky et al., 1995). All BSRN data were quality controlled with manual screening and application of the relevant definitive tests described by Long and Shi (2008). The manual screening removed suspect data and shadows from station structures. The BSRN tracker measurements were supplemented where there were missing data by the SUM from the ARM QCRAD value-added product from the neighboring ARM station, which is also based on Long and Shi (2008). The resulting data set was used as an intermediary processing step for two purposes: first, to provide a baseline to aid in identification of shadows on the D-ICE instruments and second to provide a statistical baseline for correcting or validat- ing the aforementioned sources of uncertainty in the D-ICE measurements.

\subsubsection{Quality-controlling D-ICE data}

\section{Light pollution}

The amount of light pollution from the camera LEDs measured by the pyranometers was determined empirically for each instrument by comparison to nighttime periods on 1920 and 30 September and 1-2 October 2017 when the illumination was switched off. The calculated biases were then subtracted in post-processing when the lights were on. These biases were small, ranging from $\sim 0-1.5 \mathrm{~W} \mathrm{~m}^{-2}$ (mean, $0.35 \mathrm{~W} \mathrm{~m}^{-2}$ ).

\section{Shadows}

Light poles, as well as some additional station structures such as nearby aerosol inlet pipes, were minimal obstructions to the view of the sky by the radiometers except for episodic appearances of shadows on clear days that reduced the signal in the pyranometers. The shadows occurred at different solar azimuth and zenith angles for each pyranometer and were only present when the sun was unobstructed by clouds. The times when each instrument was shadowed were identified by a reduction of normalized total irradiance signal exceeding $-3 \%$ in the pyranometers relative to the SUM (Sect. 2.3.2) when the direct beam accounted for at least $25 \%$ of the irradiance, which was qualitatively determined 
to be a suitable threshold for when shadows were observed to appear. This method for detection of shadows was supplemented with manual screening. Cases of shadows and ice co-occurring were treated as shadows and removed from the analysis of biases associated with ice. Approximately $1 \%-$ $4 \%$ of the data was removed, depending on the location of the instrument.

\section{Outlier detection}

Data from each D-ICE radiometer were processed with the same Long and Shi (2008) procedures as the operational systems. This was followed by manual screening. One radiometer (a1571), which is typically operated unventilated, was experimentally set in a ventilator that was later found to shadow its thermopiles. Another (26214) was unlevel, but without the possibility of re-leveling after installation. Both of these radiometers are excluded from the radiometric analyses and $\mathrm{BE}$ product but are included in the analysis of the ventilator deicing performance in Sect. 4.1.

The Long and Shi (2008) "QCRAD" approach is designed to identify outliers relative to the data stream being screened. It therefore relies on the assumption that most of the data fall within normal limits and is only sensitive to data that do not. Figure 2 shows examples of the "climatological configurable limits" for a D-ICE pyranometer in panel (a) and a pyrgeometer in panel (b). Since occurrences of icing rarely produce signals that fall outside the statistical distribution, the spurious data are not readily captured by outlier-detection methodologies, such as QCRAD. For example, the secondlevel threshold for the definitive configurable QCRAD limit flagged $<3 \%$ of the iced data in Fig. 2a (green line). Similarly, $>99 \%$ of the $\sim 900 \mathrm{~h}$ of iced LWD in Fig. 2b passed the QCRAD climatologically configurable limit test.

\section{Icing}

The results from the processing of the D-ICE images were used to flag data contaminated by the presence of ice on the radiometer domes. These data were removed from the $\mathrm{BE}$ data set, but a second version with occurrences of icing preserved was needed to calculate the biases caused by the ice. To construct such a data set, only data that had been rejected for failing physically possible limit tests or having been determined to be shadowed were removed, while outliers flagged using other tests that were within physically possible limits when ice was present were retained.

\section{Infrared loss corrections}

Infrared loss corrections were applied to pyranometers that exhibited nighttime offsets following the method of Dutton et al. (2001) (see Table 1), though the offsets observed during D-ICE were consistently small (generally $<3 \mathrm{~W} \mathrm{~m}^{-2}$ ). Interestingly, two systems that feature air intake tubes extending below the ventilator fan (MeteoSwiss and Eigenbrodt
480) were found to have nighttime offsets in the CM11 instruments they housed that were uncorrelated with the net longwave $\left(r^{2}<0.05\right)$ but highly (negatively) correlated with wind velocity $\left(r^{2}=0.54-0.55\right)$; this was also somewhat true for the CM11 and PSP in the PMOD ventilators $\left(r^{2}=0.22\right.$ $\&$ 0.36). What each of these systems have in common is that they were both heated and vulnerable to airflow obstructions. We interpret the source of this bias to be clogging from blowing snow that reduced aspiration thereby allowing the heating element to differentially warm the ventilator and radiometer case, which would be expected to produce a similar voltage offset as infrared loss. Clogging has also been reported in similar ventilators by the Sonnblick BSRN station, and a longer set of inlet tubes were constructed there that alleviated the problem (Weisser, 2016). For D-ICE, we corrected the affected pyranometers in the MeteoSwiss and Eigenbrodt 480 analogously to Dutton et al. (2001) using the wind measurements despite a limited understanding of how the bias would translate under sunlit conditions, but note that the corrections were small (the mean of the more severely affected instrument was $\sim 3 \mathrm{~W} \mathrm{~m}^{-2}$ ) and served to bring the measurements closer to the mean of the others.

\subsubsection{Best estimate fluxes}

The BE data set was produced by averaging the calibrated, bias-corrected, ice-free, and quality-controlled D-ICE data streams. For LWD, this consisted of all 8 upward-facing pyrgeometers ( 5 from D-ICE, 2 from NSA and 1 from BSRN). For SWD, this consisted of 17 pyranometers from D-ICE, the global BSRN, and the global NSA. Since the sensitivity of a thermopile is not precisely isotropic, the calibration of global pyranometers is designed to be well-suited for the daily average but prone to varying errors through the day as the incident angle of the direct beam changes. Thus, to produce a BE, the average of the global pyranometers could be used to constrain the SUM from the trackers, or the tracker measurements could be used to bias-correct the average of the global pyranometers. We chose to do the latter because the large number of included data streams produces a data set less prone to discontinuities and noise and importantly was also directly verified as ice-free (Sect. 2.3.1). Thus, the SWD average was bias-corrected as a function of solar zenith angle (SZA) and the diffuse fraction using the SUM; the magnitude of the correction varied between $0.5 \%$ and $3 \%$ depending on the diffuse partitioning.

\subsubsection{Uncertainty calculations}

Uncertainty is estimated empirically as the $1 \sigma$ spread between the $1 \mathrm{~min}$ average measurements from the different sensors where fluxes are available from at least two radiometers. Only the data that passed quality control procedures and were determined to be ice-free are included. Thus, the number of measurements used in the calculation of uncertainty 

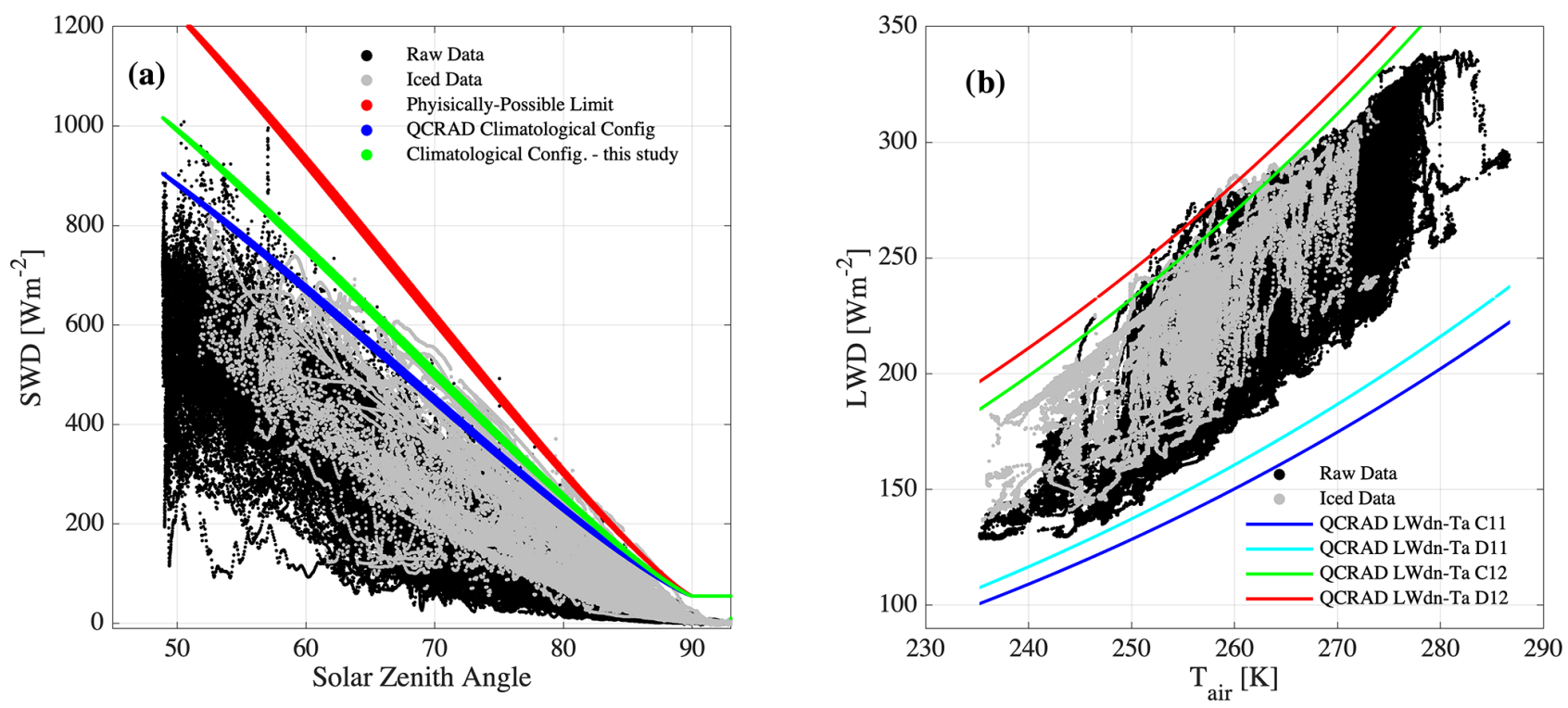

Figure 2. Examples of climatological configurable limit tests from Long and Shi (2008) for SWD (SN F16305R) (a) and LWD (SN 28507) (b). The figures are comparable to Figs. 1 and 9 from Long and Shi except that 1 min averages are shown here instead of 15 min. Black points are ice-free, and grey points are contaminated with ice. The colored lines are suggested thresholds for rejection of data of varying degrees of strictness.

can be less than the total number of instruments, but this limitation does not significantly impact the uncertainty calculation as evidenced by the fact that the result is uncorrelated with the number of systems used in the calculation for both LWD and SWD. Nevertheless, the uncertainty may be best understood by its bulk properties: uncertainty in LWD is shown in Fig. 3a plotted against the mean net longwave flux from the pyrgeometer thermopiles (this differs from, but is correlated with, the net longwave of the natural surface). The solid line is the mean of the 1 min resolution uncertainties in bins of $1 \mathrm{~W} \mathrm{~m}^{-2}$ of the net longwave, and the shading is $\pm 1 \sigma$ of the same. Large negative net longwave values are indicative of clear skies, while the value is generally greater than $-20 \mathrm{~W} \mathrm{~m}^{-2}$ in the presence of optically thick clouds. The BSRN target uncertainty is $3 \mathrm{~W} \mathrm{~m}^{-2}$ (McArthur, 2005); the average for D-ICE is $2.6 \mathrm{~W} \mathrm{~m}^{-2}$. The absolute accuracy of pyrgeometers at Utqiagivik based on in situ calibration to a common standard has been shown previously to be $\pm 2 \mathrm{~W} \mathrm{~m}^{-2}$ (Marty et al., 2003). The uncertainty is larger for clear skies and smaller for cloudy skies. This is not surprising because clear skies are anisotropic and spectrally complex in the infrared. In the Arctic, the precipitable water vapor is commonly $<1 \mathrm{~cm}$ during clear skies, which causes the farinfrared to become semi-transparent (e.g., Cox et al., 2015). Under such conditions, instrument-dependent biases of -2 to $-6 \mathrm{~W} \mathrm{~m}^{-2}$ in pyrgeometers have been reported with respect to windowless longwave radiometers (Gröbner et al., 2014).

Uncertainty in SWD is plotted Fig. 3b as a function of SZA. In addition to absolute units, the uncertainty is also shown in relative units (\%). The BSRN target uncertainty for pyranometers is $2 \%$ (McArthur, 2005), a condition that is met, and the uncertainty is relatively flat when the SZA is $<70^{\circ}$. When the SZA is larger, the relative uncertainty is larger too, but the absolute uncertainty is $<5 \mathrm{~W} \mathrm{~m}^{-2}$, which meets the standard for the minimum expected error (McArthur, 2005).

\section{Biases caused by ice}

To better understand the consequences of icing, Fig. 4 shows a case study for LWD from late January in panel (a) and for SWD on 14-15 April in panel (b). Analysis of these cases, next, is followed in Sect. 3.3 with a more general calculation of biases at the monthly scale.

\subsection{LWD icing case}

The LWD time series spans approximately two weeks and shows a range of LWD typical of the Arctic winter, from $\sim 140 \mathrm{~W} \mathrm{~m}^{-2}$ during the coldest, clearest times to $\sim 280 \mathrm{~W} \mathrm{~m}^{-2}$ during the warmest, cloudiest times. The blue line in Fig. 4a is the LWD BE, and the grey shading is the uncertainty. The red line is the time series of pyrgeometer 28507 , which was susceptible to icing. The red shading highlights the bias caused by the ice in 28507 relative to the BE. Two events stand out: first, beginning on 22 January, a frost event completely covered 28507, shown in the inset image. The effect on 28507 can be compared to the clear dome in the neighboring pyrgeometer (34309), which was included in the BE. Second, on 27 January, a rime event caused by 

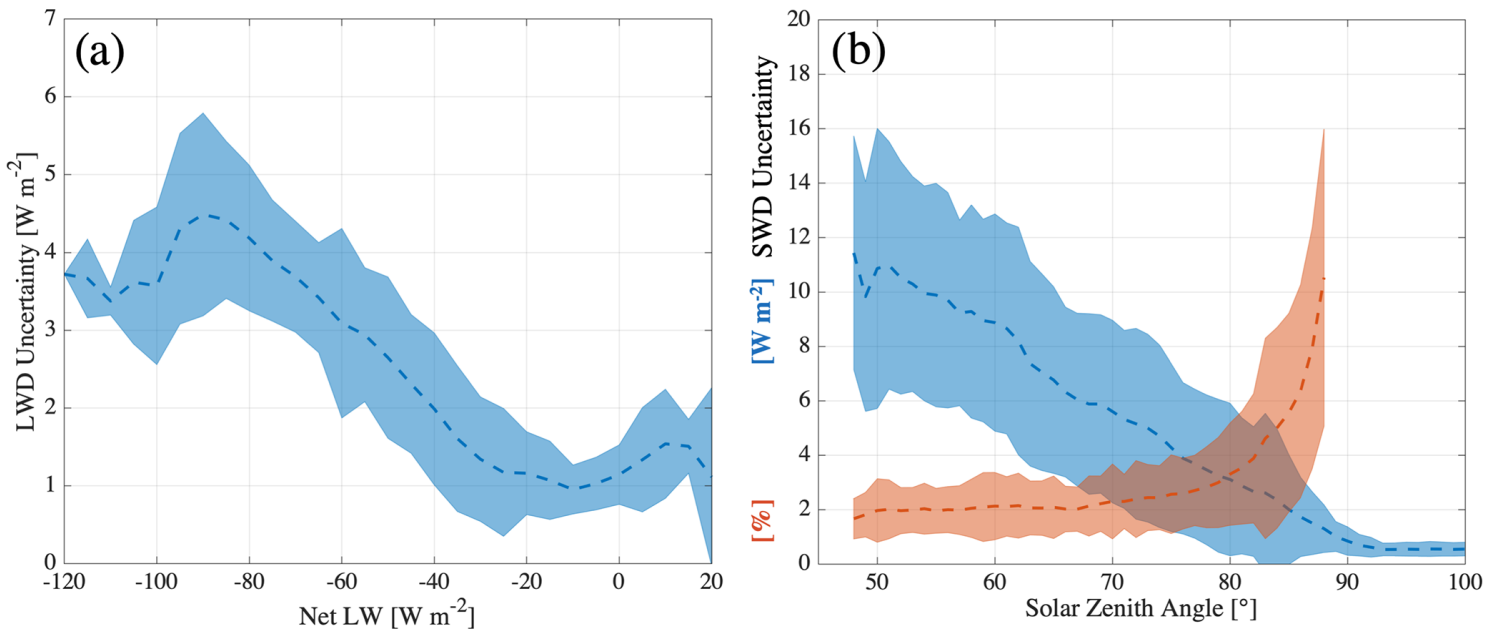

Figure 3. (a) Mean (dashed line) and $1 \sigma$ (shading) variability in calculated 1 min average uncertainties for LWD as a function of the net longwave flux represented by the mean thermopile flux of the pyrgeometers. (b) Similar to (a) for uncertainty in SWD plotted against solar zenith angle. Uncertainties in (b) are plotted in units of $\mathrm{W} \mathrm{m}^{-2}$ (blue) and relative units (red).
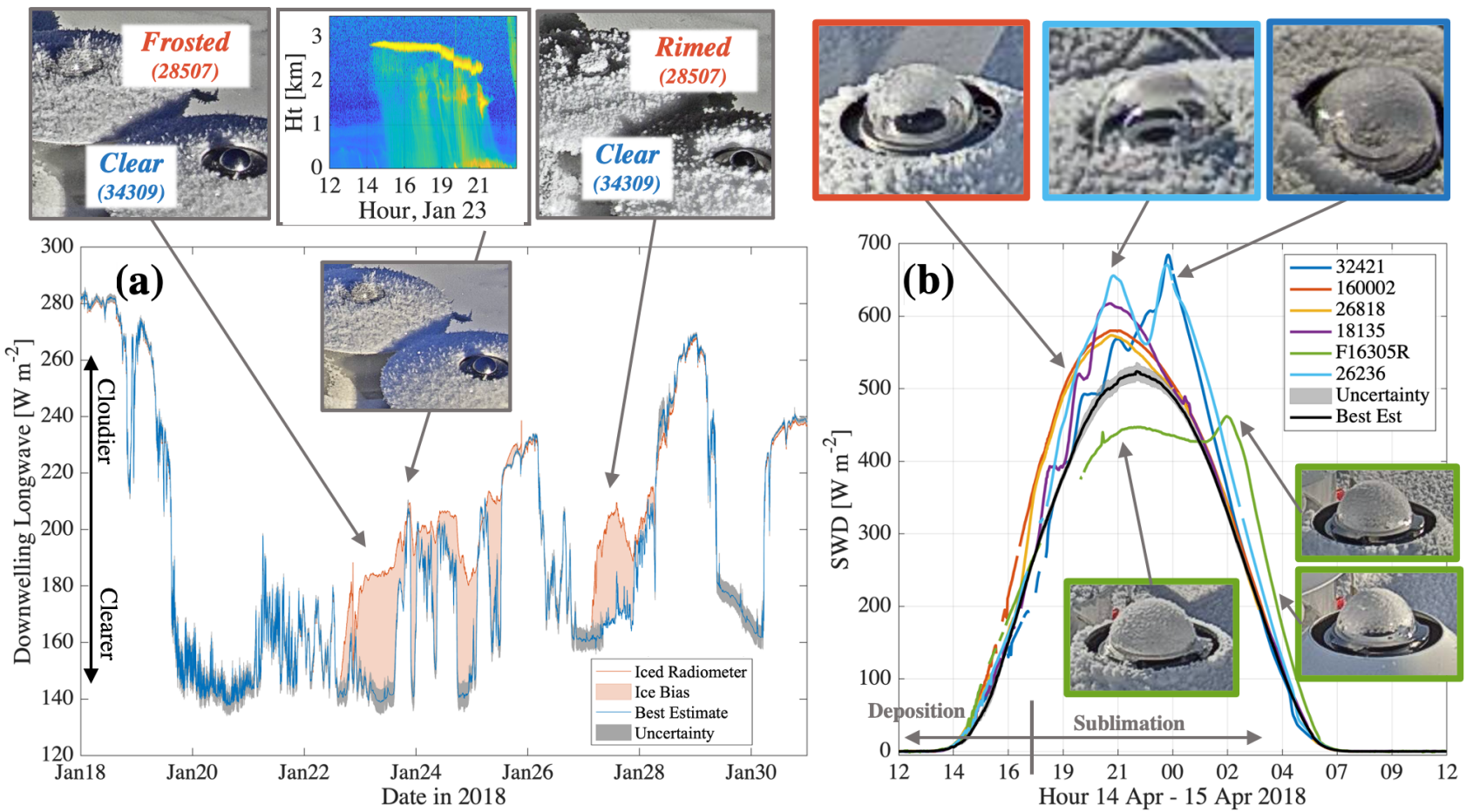

Figure 4. Case studies of icing for LWD in late January (a) and SWD during a clear day in April (b). Inset images show the condition of highlighted radiometers. The upper-center panel in (a) shows backscatter from the DoE-ARM ceilometer.

freezing fog occurred with similar results for the pyrgeometers. For both events, the biases were +40 to $+45 \mathrm{~W} \mathrm{~m}^{-2}$, with the maximum observed bias during the case study of $+58 \mathrm{~W} \mathrm{~m}^{-2}$ occurring on 25 January. (This is comparable to the maximum bias from icing observed during the campaign of $+59.5 \mathrm{~W} \mathrm{~m}^{-2}$ on 26 December, though occasionally larger biases were observed briefly in association with melting ice or snow on the dome). The systems in the figure are identical except that the radiation shield covering 34309 was lifted $2 \mathrm{~mm}$ using washers to improve airflow over the dome, highlighting the influence of small differences in ventilator design. These cases were not the only periods of severe icing during D-ICE, but the example shown was unusually impactful on 28507 and is therefore highlighted because it is instructive. The bias is largest when the sky is clear. This is because when the sky is clear, the sky emissiv- 
ity (and thus brightness temperature) is most different from that of the ice. When clouds are present, the bias is reduced to near $0 \mathrm{~W} \mathrm{~m}^{-2}$. This is evidenced by the brief occurrence of an optically thick stratiform mixed-phase cloud with a liquid layer between 2 and $3 \mathrm{~km}$ late on 23 January, highlighted in the top-center panel of Fig. 4a. While this cloud was over the station, the icing conditions remained unchanged, as confirmed by review of the camera images (Fig. 4a center inset), but the flux from the ice was similar to that of the cloud because both had similar emissivity and thermodynamic temperature (as confirmed by radiosoundings, not shown). Thus, this case study demonstrates that biases in LWD can be large but are episodic in nature, depending on both ventilator performance and cloud properties, in addition to icing conditions. The bias in 28507 relative to the $\mathrm{BE}$ averaged for the time period represented in the figure is $+7.8 \mathrm{~W} \mathrm{~m}^{-2}$, which is consistent with the biases reported during brief periods of icing conditions elsewhere (Persson et al., 2018).

\subsection{SWD icing case}

Figure $4 \mathrm{~b}$ shows an example of a clear-sky day in mid-April that followed frost formation the previous night. The time during which the frost was observed to be growing through deposition ended at approximately 17:00 UTC on 14 April after which the frost sublimated during the day. The black line in the figure shows the SWD BE, and the grey shading is the uncertainty. Five pyranometers that had frost on their domes for at least some of the day are shown by the colored lines. Missing data in the figure are because of shadows.

The biases from the ice are generally positive (up to $+188 \mathrm{~W} \mathrm{~m}^{-2}$ ) but sometimes also negative (up to $-106 \mathrm{~W} \mathrm{~m}^{-2}$ ), and the maximum absolute and relative errors were not necessarily coincidental in time. These values are comparable to the largest instantaneous biases observed during the campaign, though several occurrences on other days (e.g., 28 April) of negative biases as large as $-211 \mathrm{~W} \mathrm{~m}^{-2}$ were associated with thick pieces of ice and snow that accumulated on the lee side of the dome and then later faced the direct sun. In Fig. 4b, some biases (e.g., 160002) manifest as an apparent shift in the solar cycle, but the data appear otherwise physical. Note that the thickness and density of the ice in the example images (insets in figure) is qualitatively similar. The main difference between the images is in the coverage of the ice. The dome of both the pyranometers (32421, F16305R) that exhibited negative biases during the day were entirely covered by ice when the negative biases were observed; the bias was negative because the irradiance was attenuated. In contrast, the ice on the domes of the other affected radiometers (and also F16305R and 32421 later in the day) was concentrated near the top of the domes. This is a condition commonly observed on ventilated radiometers that is colloquially known as "capping". Capping is thought to be the consequence of the ventilator being least efficient in circulating air over the top of the dome; thus, deposition

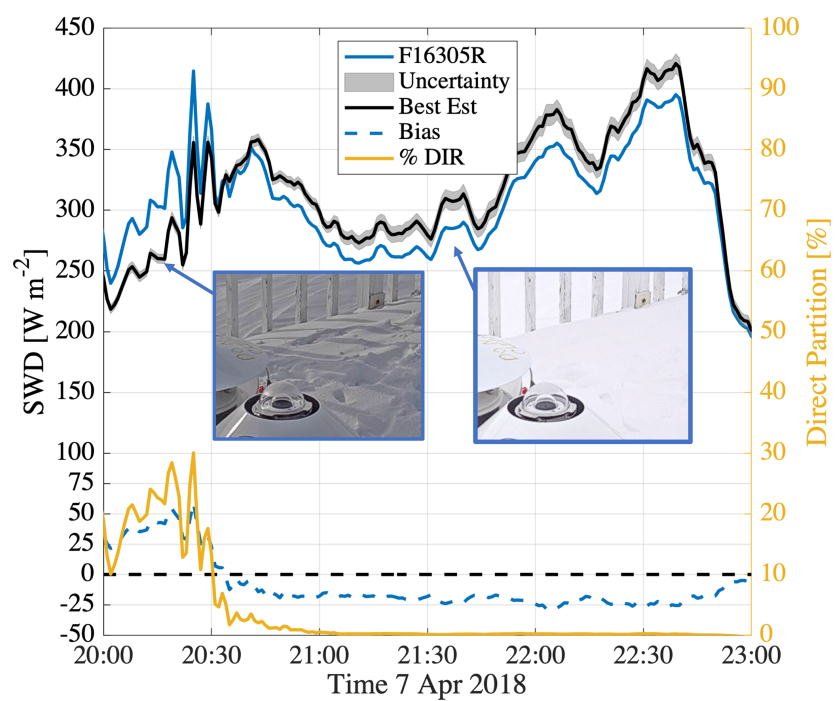

Figure 5. Case study of SWD on 7 April 2018. The solid black line and grey shading are the best estimate and uncertainty; the solid blue line is an iced pyranometer shown in the inset images. The dashed blue line is the bias in the solid blue relative to the solid black, and the yellow line shows the percent of the irradiance contributed by the direct beam: when this value is near zero, the lighting is diffuse under overcast conditions.

typically occurs at the top of the dome first and ice in this location also takes longer to sublimate. The contrast between the negative bias during the early and middle parts of the day and the biases of the capped radiometers, including F16305R and 32421 as they began to sublimate later the day, is notable: while not definitive, it suggests that capping tends to result in positive biases, at least during relatively low sun angles (the maximum solar elevation angle for this case was $28.3^{\circ}$ ) when the direct beam passes largely uninhibited through the clear portion of the dome and the signal is enhanced by scattering towards the thermopile by the ice at the top of the dome.

To illustrate the influence of ice during diffuse conditions, another example from 7 April (Fig. 5) shows the transition from a positive bias (dominated by scattering) to a negative bias (dominated by attenuation) in F16305R capped with ice due to a transition in lighting. From 20:00 to 20:30 UTC the direct beam is present, being $10 \%-30 \%$ of the total irradiance, during partly cloudy conditions. At that time, a bias of up to $+50 \mathrm{~W} \mathrm{~m}^{-2}$ is observable after which the bias becomes negative, about $-25 \mathrm{~W} \mathrm{~m}^{-2}$, as overcast conditions obscure the sun and the lighting becomes entirely diffuse.

These cases demonstrate that errors from ice in SWD can be large and that the sign of the bias is dependent on the amount of coverage of ice on the pyranometer dome, as well as the presence, and likely also the angle, of radiation from the direct beam. 


\subsection{Biases from ice in monthly means}

Figure 6 shows monthly mean biases in LWD (panel a) and SWD (panel b) for each radiometer. For each cell, the color indicates the bias associated with frost, rime, snow, or liquid (usually ice melted by heat from the ventilator). The monthly means are also plotted as a time series in panels (c) and (d) with the aggregate means shown by solid lines. Note that the months of July and August include limited amounts of data because of beginning and end dates of the campaign. All bias calculations are corrected to account for differences between individual radiometers and the BE that are associated with calibration uncertainty. The bias calculations are insensitive to the determination of ice occurrences from the images because the average of all conditions, regardless of ice presence, is calculated.

As noted in Sect. 3.1, the LWD case study was chosen because it was a particularly influential event, and a particularly susceptible system was highlighted. Figure 6 shows that when data are averaged for long periods of time, the bias in icing of pyrgeometers is actually small. Indeed, only two radiometers, BSRN and 28507 (having similar configurations and equipment), exhibit biases that are detectable relative to the average uncertainty (Fig. 3). The most severely affected month was January when the average bias was just $+1 \mathrm{~W} \mathrm{~m}^{-2}$ and the most affected system was biased $+4 \mathrm{~W} \mathrm{~m}^{-2}$. Note that some experiments were conducted during icing periods on four days ( $82 \mathrm{~h}$ total) in the first week of January (described later in Sect. 4) and that these times were rejected from the analysis in the figure.

SWD icing biases during D-ICE occurred from February through June with a peak in April. This is because biases in SWD depend both on the amount of sunlight and the amount of icing, which have opposing seasonal cycles. The opposition is slightly out of phase such that in autumn there was too little sunlight when the icing first began in earnest, but that both substantial amounts of sunlight and icing co-occurred during spring. Recall from Sect. 2.2 that the beginning of the icing season was late during D-ICE and that in a more typical year at Utqiagivik some biases may also have been observed in September and October. Note that the calculation includes the average of both negative and positive biases. If the average of the absolute value of the bias is plotted instead (not shown), the biases increase slightly but interpretation is hampered by the fact that noise contributes to the bias calculation rather than canceling out. Nevertheless, the results indicate that biases in pyranometers at D-ICE were dominated by positive perturbations, which is consistent with spurious data being principally tied to a combination of clear skies, low sun angles, and capping in early spring.

\section{Ice mitigation}

\subsection{Performance of ventilators}

To assess ventilator performance, we begin with two qualitative examples that broadly illustrate the influence that heating and ventilation have in mitigating ice. The first example is of a freezing fog event that occurred from 12:30 UTC on 5 January with rime accumulation continuing until about 09:00 UTC on 6 January. The image in Fig. 7a shows the status of the systems during the event at 19:00 UTC on 5 January. At this time, rime is observable on the domes of some of the systems while most remain ice-free. Immediately after these images were taken, the power was deliberately cut to the ventilators and the radiometers began accumulating ice immediately, being iced over within $2.5 \mathrm{~h}$ (Fig. 7b). The second example began on 21:30 on 9 January when the RHI $>100 \%$, but no active icing was observed, the instruments were intentionally iced by manually spraying water on the domes, and de-icing was monitored for $9 \mathrm{~h}$ before the experiment was ended by the onset of a natural riming event. Of the 25 tested systems, 17 successfully de-iced within the $9 \mathrm{~h}$ window in the supersaturated conditions (mean $6 \mathrm{~h}$, minimum $0.25 \mathrm{~h}$ ). The systems that de-iced the fastest were those that featured heating elements, though several unheated systems were observed to de-ice themselves.

To quantify performance over the course of the campaign, Fig. 8 shows a summary of statistics from the systems at DICE, NSA, and OLI based on the classification of the images described in Sect. 2.4.2. The systems are labeled on the $x$ axis, and the $y$ axis shows a simple performance metric, which is calculated thusly:

$P=100 \times\left\{\left[\frac{t_{i, \text { iced }}}{t_{\text {icing }}}\right]-1\right\}$,

where $P$ is the ice mitigation performance in units of percent, $t_{i \text {,iced }}$ is the amount of time system $i$ was iced, and $t_{\text {icing }}$ is the amount of time icing conditions occurred. Therefore, when $P=0 \%$, the amount of time the radiometer was iced and the amount of time icing occurred are the same; i.e., the de-icing system had no effect. When $P<0 \%$, the value expresses the percent of time during icing conditions that the system successfully mitigated ice, with a minimum of $-100 \%$ (all icing mitigated) because $t_{i}$,iced cannot be less than 0 . Instances where $P>0 \%$ indicates that the radiometer was iced more frequently than icing conditions occurred, suggesting that the ventilator exacerbated icing. Positive values of $P$ can theoretically reach infinity because $t_{\text {icing }}$ is independent of and can

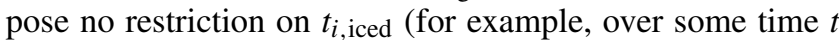
if no icing conditions are observed but radiometer $i$ was iced then $t_{\text {icing }}=0, t_{i \text {, iced }}>0$ and $P=\infty$ ).

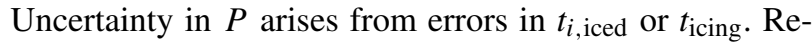
call from Sect. 2.4.2 that the identification criteria for the status of the individual radiometers $\left(t_{i, \text { iced }}\right)$ is that all ice is flagged, regardless of coverage, density, or thickness. This 
(a)

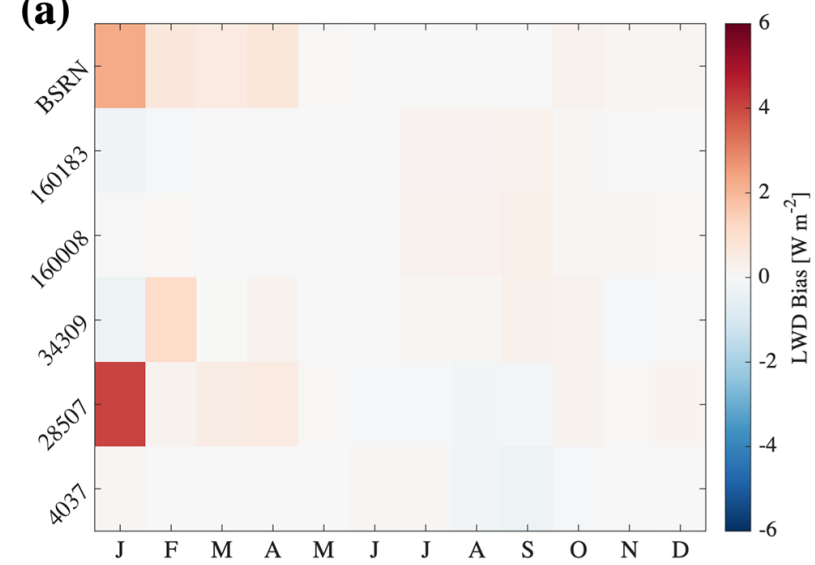

(c)

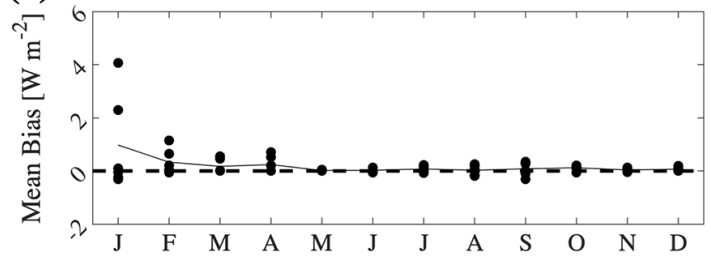

(b)

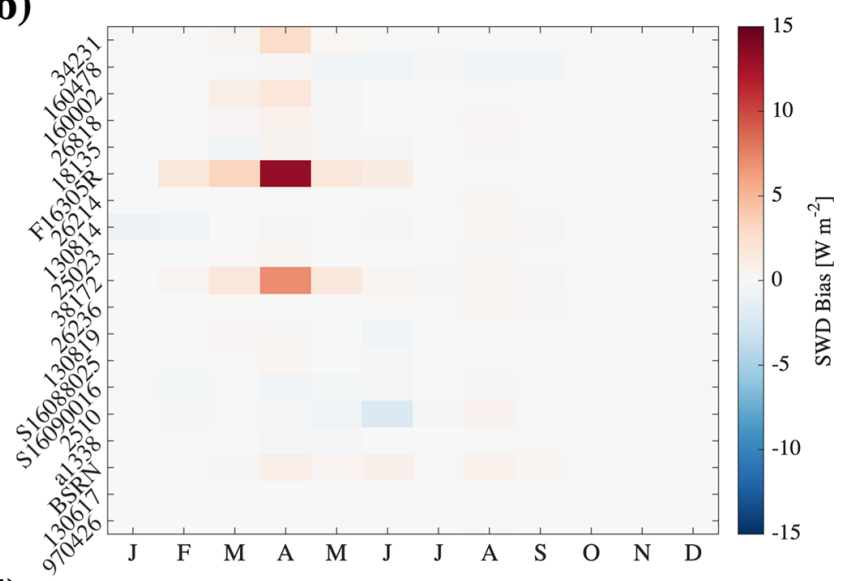

(d)

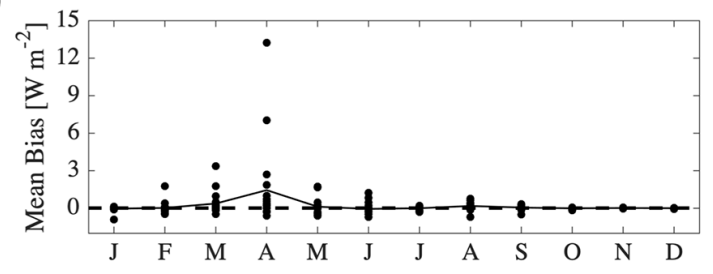

Figure 6. Calculations of biases in monthly means relative to the BE for LWD (a, c) and SWD (b, d). (a, b) show individual instruments and months; the same data are plotted in time series form in the (c, d) for reference. All calculations are corrected for statistical differences between individual radiometers and the $\mathrm{BE}$ when ice-free. The calculations are for all conditions, not just times when ice was present.

criterion is advantageous because it is an objective threshold for icing but also has the disadvantage that instances of very light icing could be missed during classification. To attempt to understand the uncertainty in $t_{i \text {,iced, }}$, we compared systems that were treated most similarly (the two MS80, two SW CVF4, two LW CVF4, and two VEN/PSP systems). We found that the differences were between $2 \%$ and $20 \%$, averaging to $8.5 \%$. We acknowledge that we do not have a robust way to calculate this uncertainty, but it is likely conservative because while some of the observed difference reflects error in the classification, the treatment of the compared systems was not precisely the same nor can local variability in icing be ruled out, and upon review some differences between similar systems are found to be real (see below). Identification of events $\left(t_{\text {icing }}\right)$ is subjective and uncertain as well, in particular in determining the end time for an event. However, uncertainty in $P$ due to uncertainty in $t_{\text {icing }}$ is a constant applied to all radiometers. Consequently, the magnitudes of $P$ in Fig. 8 may be biased but if so are biased uniformly, while the relative differences in $P$ between the systems have uncertainties of approximately $10 \%$ based on the comparison between like systems. Particular caution should be exercised in interpreting the differences between the sites, D-ICE, NSA, and OLI, because $t_{\text {icing }}$ was determined independently for each.

While no systems were found to be $100 \%$ effective, twothirds of the systems, including all those housing pyrgeometers, were effective at least $80 \%$ of the time and 15 out of 34 were effective at least $90 \%$ of the time. The average was
$77 \%$, but there was also a substantial amount of variability $(\sigma=30 \%)$ and five systems were found to mitigate ice $<50 \%$ of the time. One of these was observed to increase icing. The positive value of $P$ for this system, F16305R, is consistent with subjective analyses that indicated ice (likely frost) on the F16305R's dome when no ice was present on the ventilator or nearby structures. While we do not know the explanation for this behavior, the most noticeable design element of F16305R's ventilator (which was unheated) is that the aspiration vent around the base of the dome is larger than any of the other systems. It is plausible that this could produce a low-pressure pocket around the dome that could support deposition.

Interestingly, the CMP22 outperformed the SMP22 in the CVF4 by $20 \%$ despite the similarity between the ventilation systems and the radiometers. The only difference was that on 6 January the air intake screen on the CVF4 holding the SMP22 was removed to assess whether clogging by snow and reduced air flow impacted effectiveness. The CMP22 was observed to outperform the SMP22 by $19 \%$ prior to this change and $21 \%$ after, so the difference is not attributable to the presence of the screen and the screen apparently had little impact on effectiveness. We do not know the explanation for the observed difference.

In general, mitigation of ice on pyrgeometers was more effective than pyranometers, even for cases when the systems were otherwise similar (e.g., CVF4 and VEN systems). There are several plausible, but not mutually exclusive, ex- 

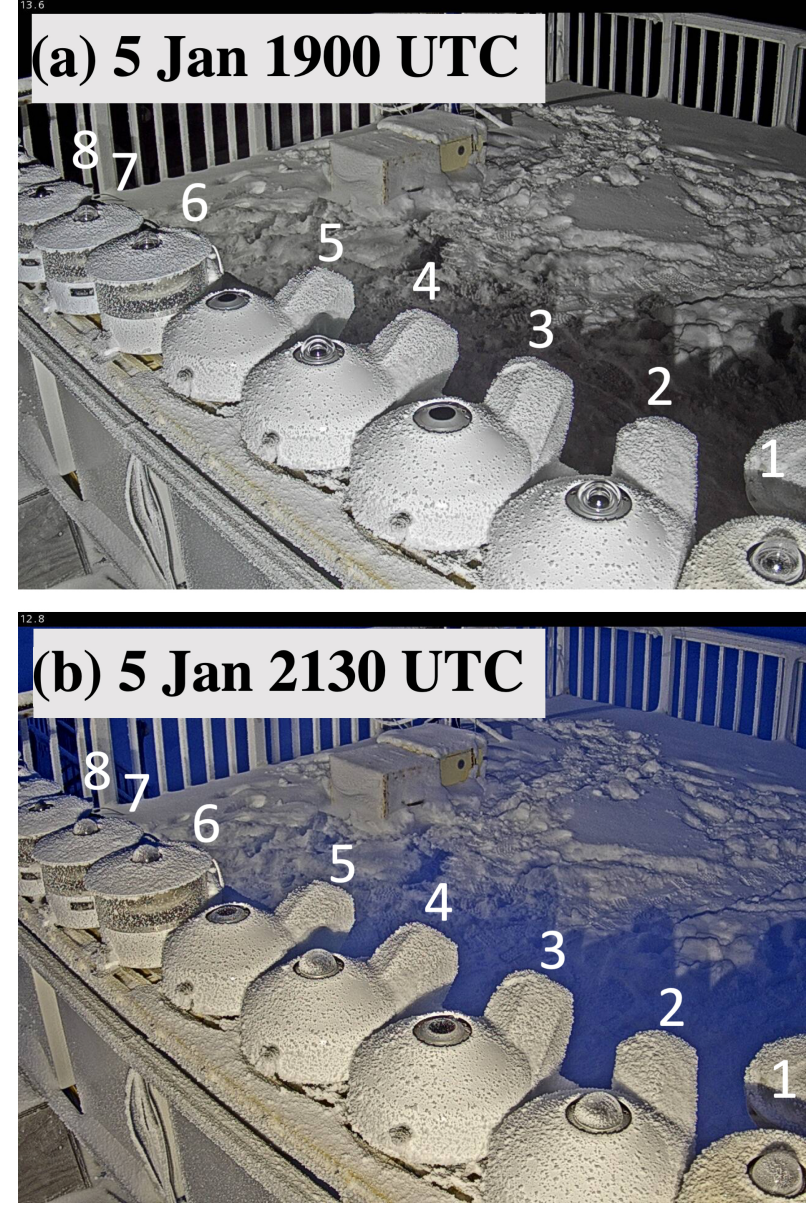

Figure 7. From CAM1, a freezing fog event in progress on 5 January and resulting in riming. (a) Ventilators operating normally during the riming event. (b) After the image in (a) was captured, the ventilators were unpowered resulting in icing on domes after several hours of equilibration. Numbers refer to the system positions from Fig. 1b.

planations for this: first, the domes of the pyrgeometers are smaller and have a lower profile, and therefore aspirated air may be more easily circulated to the top of the dome; second, the smaller surface area of the dome supports improved conduction of heat, as does the fact that pyrgeometer domes are constructed of silicon, which is more thermally conductive than the quartz pyranometer domes; and third, more speculatively, the outer coatings of the domes may be less prone to accretion of ice.

\subsection{Physical mechanism}

Successful mitigation of ice is demonstrated by systems in Fig. 8 that were not equipped with heaters. This supports the heuristic within BSRN that ventilation of ambient air alone can be effective. However, it is counter-intuitive because aspiration of saturated air increases rather than decreases depo- sition rates, specifically resulting in denser, but not necessarily thicker, frost (Kandula, 2011, and references therein).

We examined the properties of the Eppley ventilation system configured similarly to those in use at the Barrow BSRN station to help elucidate the attributes that contribute to effectiveness in the absence of heating elements. The tested system is an Eppley VEN housing a high-flow $80 \mathrm{cfm}(10.3 \mathrm{~W})$ DC fan (Delta Electronics FFB0812EHE) modified with bearings rated for low temperature; examples of such systems at D-ICE are in positions 6-9 and 24 (Fig. 1b). When the fan is operated outside of the ventilator, the velocity of the air downstream is $\sim 9.8 \mathrm{~m} \mathrm{~s}^{-1}$. When installed in a standard VEN configuration, the maximum velocity measured near the top of the dome is $7.7 \mathrm{~m} \mathrm{~s}^{-1}$. When the shield is lifted to improve airflow, the velocity increases to $8.6 \mathrm{~m} \mathrm{~s}^{-1}$ for a $1 \mathrm{~mm}$ lift and to $9.3 \mathrm{~m} \mathrm{~s}^{-1}$ for a $2 \mathrm{~mm}$ lift (as in positions 6 and 8$)$.

Figure $9 \mathrm{a}$ shows a $9 \mathrm{~h}$ time series of temperatures collected during D-ICE in January 2018. The dome temperatures from PIRs 28507 and 34309 were $0.5-0.6^{\circ} \mathrm{C}$ warmer than the ambient air temperature and differed from each other by about $0.15^{\circ} \mathrm{C}$. On 5 January both fans were shut down simultaneously and the dome temperatures agreed after equilibration to ambient conditions (difference $0.01^{\circ} \mathrm{C}$ RMSE). Thus, the $0.15^{\circ} \mathrm{C}$ difference represents a real difference in temperature and not uncertainty. We will return to this later.

The fan in 34309 was turned off shortly before 20:00 UTC on 8 January for $\sim 30$ min before being turned on again. It was then turned off a second time at $\sim 21: 00$ UTC for $\sim 60 \mathrm{~min}$. As observable in Fig. 9a, in both cases the dome temperature decreased $\sim 0.6^{\circ} \mathrm{C}$ to the ambient $2 \mathrm{~m}$ air temperature measured by the station. The fan in 28507 ran continuously during the experiment and its dome temperature responded only to changes in meteorology. At $-25^{\circ} \mathrm{C}$, a $0.6^{\circ} \mathrm{C}$ increase in temperature subsaturates air (with respect to ice) with an RHI as high as $105 \%$, which is a higher supersaturation than typically occurs. Thus, the heat added by the fan is sufficient to explain the effectiveness of the ventilators without heating elements.

To better understand the sources of the heating, the experiment was repeated under controlled conditions in a laboratory in Boulder, Colorado. First, an FFB0812EHE was placed in a cold chamber without the VEN, and a thermocouple (Type T; Copper-Constantan) was positioned in the air stream $\sim 10 \mathrm{~cm}$ from the fan. The apparatus was allowed to equilibrate to $-15^{\circ} \mathrm{C}$ for several hours without the fan running after which the fan was started using an external control and a temperature increase of $0.35-0.4{ }^{\circ} \mathrm{C}$ was observed over the course of several minutes after which the fan was turned off again, and the temperature returned to its previous value (purple in Fig. 9b). A similar result was observed using a stock ebm-papst 8212JN that has comparable specifications to the FFB0812EHE (yellow in Fig. 9b). This test confirms that the temperature increase observed at D-ICE was supported by the fan independent of the ventilator. 


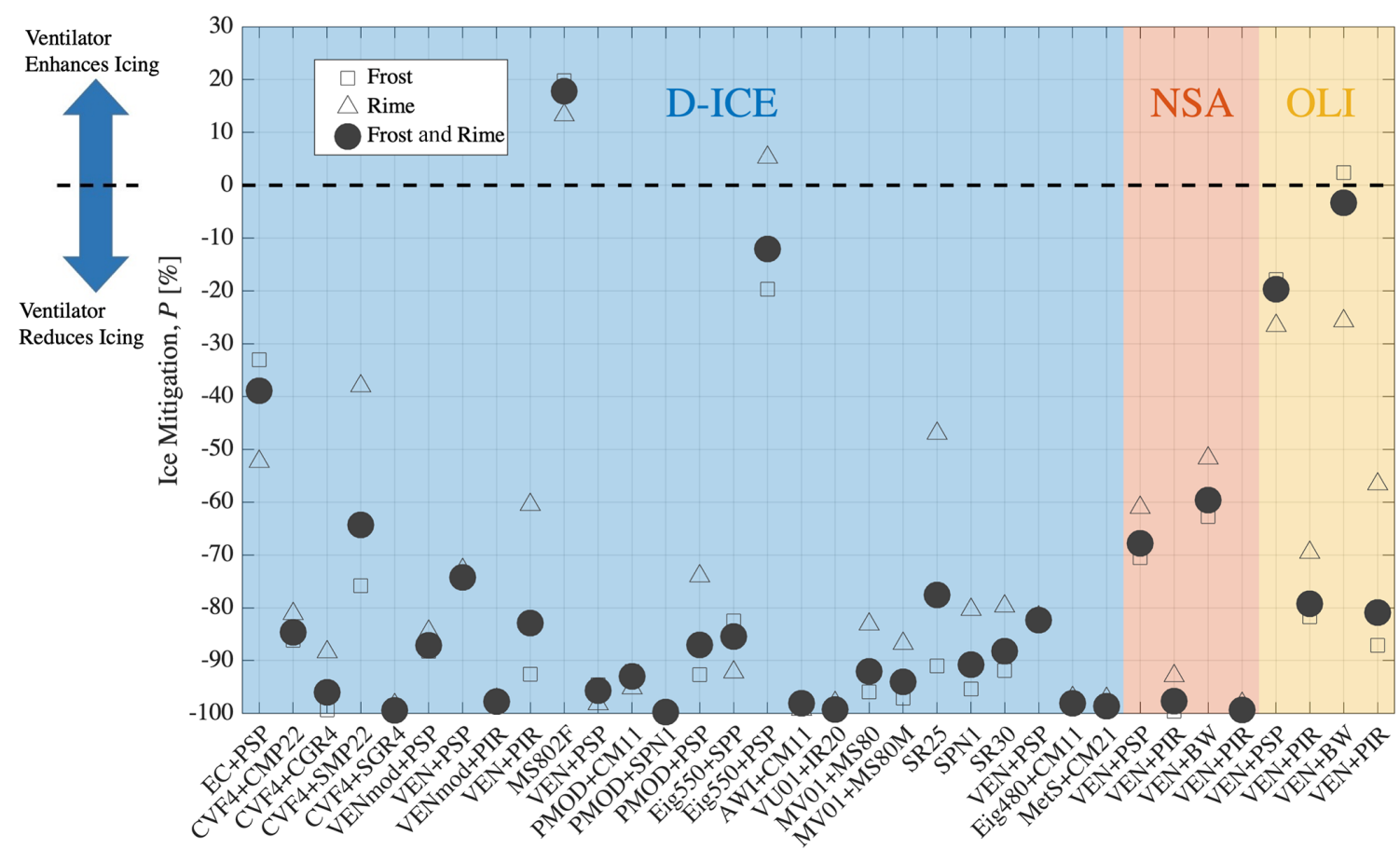

Figure 8. Ice mitigation performance metric, $P$ (Eq. 1 from main text), for tested systems at D-ICE (blue background) and DICEXACO (Utqiagivik "NSA" in red, Oliktok Point "OLI" in yellow). Solid circles refer to a combination of rime and frost while open squares are frost only and open triangles are rime only.

Next, the experiment was repeated again using an FFB0812EHE installed in a VEN containing a PIR and having a shield with a $1 \mathrm{~mm}$ lift and clay sealing around the shield edges. Similar to the previous iteration, a $0.39^{\circ} \mathrm{C}$ increase in dome temperature occurred (blue in Fig. 9b). The case temperature increased by the same amount (red in Fig. 9b), slightly lagging the dome because the case thermistor is more deeply embedded within the radiometer's mass. Both case and dome equilibrated within $1 \mathrm{~h}$. After the fan was turned off, the system re-equilibrated to within $0.05^{\circ} \mathrm{C}$ of its unperturbed state after $3 \mathrm{~h}$. Finally, the experiment was repeated two more times with changes to the height of the lift of the radiation shield (thin blue lines in Fig. 9b). When the shield was lifted to $2 \mathrm{~mm}$, the equilibrated temperature increased relative to the $1 \mathrm{~mm}$ lift, and when no lift was provided the smallest temperature increase was recorded. This is consistent with the results shown earlier, which indicate that the system with the lifted shield had a warmer dome (Fig. 9a) and performed better overall during D-ICE (Figs. 4, 6, and 8).

The heating of the dome by the fan is principally from two sources. The first is heating of the air moving past the fan motor, which is warmed by waste energy. This can be calculated by first estimating the amount of waste heat in watts, $H$, from the static pressure reported by the manufacturer, $S$, and the observed volume, $V$, moved by the fan in $t$ seconds,

$H=1-\frac{S V}{t}$, and then finding the temperature increase, $T_{w}$, associated with $H t$ Joules applied to the same volume,

$T_{w}=\frac{H}{c_{\mathrm{p}} \rho V}$,

where $c_{\mathrm{p}}$ is the specific heat of the air at constant pressure, and $\rho$ is the air density. Note that Eq. (3) neglects energy that is radiated or conducted away.

The second source is that the air downstream immediately in contact with the radiometer necessarily comes to rest and thus undergoes an adiabatic compression. This topic has been studied extensively for high velocity flows (e.g., Thompson, 1968; Lenschow, 1972), but less at low velocities. At low velocities, the properties of the gas can be approximated as ideal. Therefore, we formulate the problem from the first law of thermodynamics beginning with the ideal gas law, differentiating as follows:

$\mathrm{d} T=\frac{\alpha \mathrm{d} P+P \mathrm{~d} \alpha}{R}$,

where $T$ is the temperature, $\alpha$ is the specific volume of the air (i.e., the inverse of the air density), $P$ is atmospheric pressure, and $R$ is the gas constant. The calculation is insensitive to the reduced density of the humid air and it is sufficient to set $R=R_{\mathrm{d}}$. The system is assumed to be in hydrostatic equilibrium such that $\mathrm{d} P=0$, and so Eq. (4) reduces to

$\mathrm{d} T=\frac{P \mathrm{~d} \alpha}{R}$. 


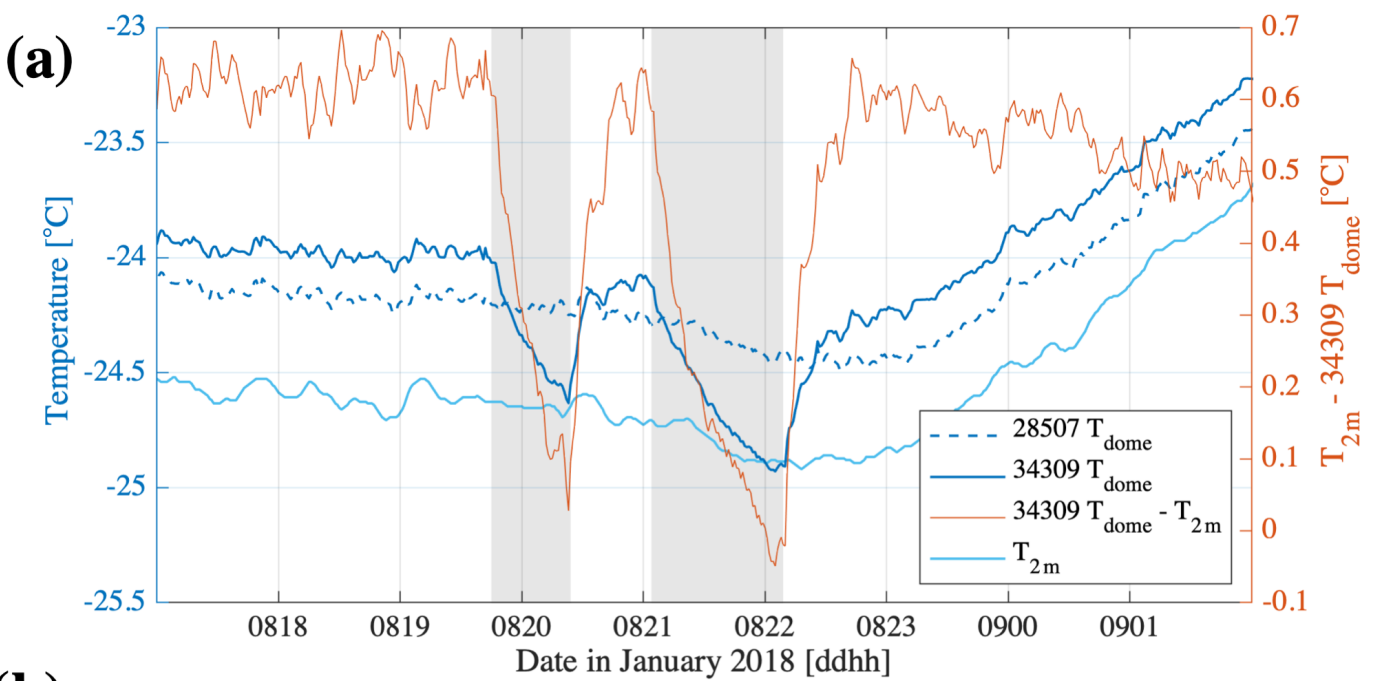

(b)
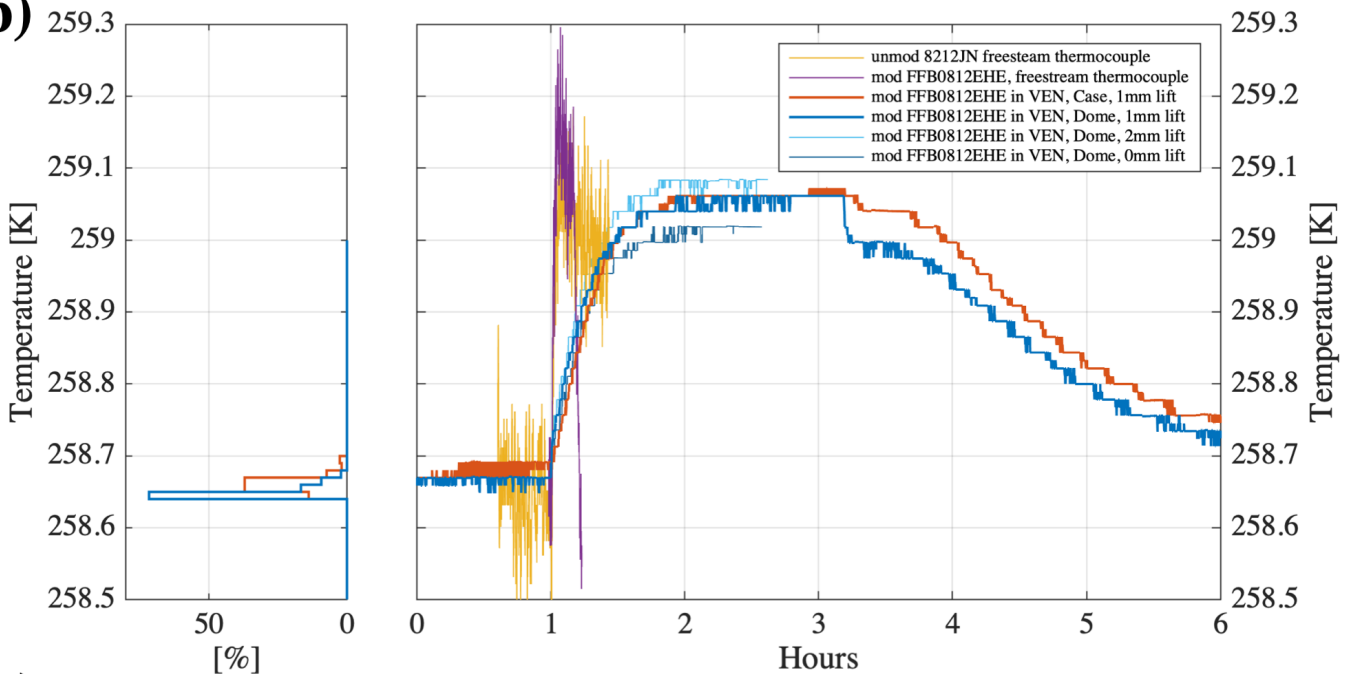

(c)

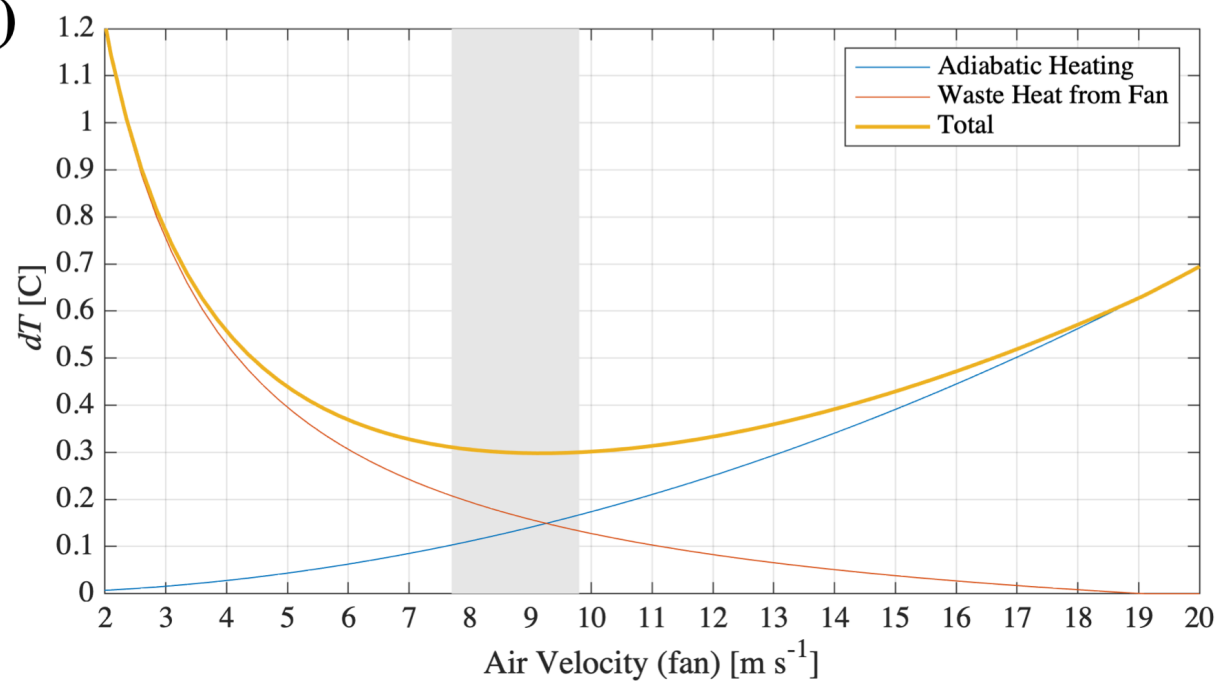

Figure 9. (a) Case study from D-ICE on 8-9 January 2018 showing the dome temperatures of PIR 28507 (dashed blue), PIR 34309 (solid blue), the $2 \mathrm{~m}$ air temperature (light blue), and the difference in the two dome temperatures (red, right-side axis). The grey shading highlights periods when the ventilator in 34309 was turned off. (b) Laboratory tests carried out in a cold chamber in Boulder, Colorado, using various configurations of the Eppley VEN ventilator housing an FFB0812EHE fan (red and blues) as well as tests with an FFB0812EHE (purple) and 8212JN (yellow) fan without the VEN. The tests are described in Sect. 4.2. (c) Theoretical calculations of heating from FFB0812EHE fan waste heat (Eq. 2) (red), adiabatic compression (Eq. 3) (blue), and the sum of both (yellow). The grey shading in (c) is the range of observed air velocities near the top of the PIR dome in an Eppley VEN. 
$\mathrm{d} \alpha$ is found as follows:

$\mathrm{d} \alpha=\alpha_{0}-\alpha_{\text {tot }}$,

where $\alpha_{0}$ is the specific volume of the air at static atmospheric pressure, $P$, and $\alpha_{\text {tot }}$ is the specific volume of the air at total pressure, the sum of the static and dynamic pressures; i.e., it is the change in specific volume caused by the compression of the air where it comes to rest at the surface of the radiometer downstream of the fan. Note that here, $\mathrm{d} T$ is treated as idealized, but that in actuality the adiabatic compression is not perfectly efficient.

The results (Fig. 9c) indicate that for the experimental setup in question, waste heat and adiabatic heating contribute similarly to the observed temperature increase in the chamber, with $\sim 44 \%\left(0.17^{\circ} \mathrm{C}\right)$ explainable by the former and $\sim 42 \%\left(0.16^{\circ} \mathrm{C}\right)$ explainable by the latter at velocities corresponding to the ventilator. The remaining $14 \%$ was unaccounted for, but apart from error this may be associated with secondary effects such as drag (Lenschow, 1972) and turbulence.

The lab experiments resulted in about half of the total heating that was observed in the January D-ICE case. D-ICE was carried out at sea level, whereas the tests in Boulder $(\sim 1500$ m a.s.l. $)$ were carried out at lower $(\sim 15 \%)$ atmospheric pressure. The field case study shown in Fig. 9a was also colder $\left(-25^{\circ} \mathrm{C}\right)$ than the chamber tests $\left(-15^{\circ} \mathrm{C}\right)$. Both of these factors increase the air density and therefore reduce the calculated temperature change. Thus, differences in the state variables do not explain the difference in fan heating observed between the field and the lab. The fan speed was monitored at D-ICE and did not indicate that fan efficiency was lower than the lab because of clogging by snow. Instead, we hypothesize that the difference could plausibly be affected by wind forcing, which also results in a compression of the air stream and subsequent heating (e.g., Thompson, 1968), in this case at the point of impact with the dome.

Interestingly, that heating from waste heat increases as air velocity is decreased (Fig. 9c) counters the observed relationship between increasing the lift of the shield and increases in both air velocity measured at the top of the dome and dome temperature. This suggests that the effect of raising the shield is to enhance the circulation of air around the dome.

\section{Discussion and conclusions}

The De-Icing Comparison Experiment (D-ICE) was carried out in 2017 and 2018 at the NOAA Atmospheric Baseline Observatory in Utqiagivik, Alaska $\left(71.3^{\circ} \mathrm{N}\right)$, in collaboration with the DoE ARM NSA (also Utqiagivik) and Oliktok Point $(250 \mathrm{~km}$ east of Utqiagivik) stations. D-ICE collected data suitable for assessing technology designed to mitigate the formation of ice on broadband radiometric stations and to quantify the influence of ice on the flux measurements. Over the course of an Arctic cold season, the status of icing on a total of 34 upward-facing broadband radiometers was monitored using cameras. Most of the radiometers were housed in ventilators that aspirated air over the sensors, sometimes heated, while others were designed with internal heating and/or ventilation. The systems were contributed by research institutes and commercial vendors and were representative of the types used by research-grade programs, such as the BSRN and DoE-ARM.

System performance, defined as the amount of time a radiometer was classified as iced normalized by the amount of time icing conditions were present (Eq. 1), was in the mean amongst the systems, a $77 \%$ reduction in the expected amount of time the systems were iced. Thus, on average the systems tested during D-ICE were successful in mitigating most ice. Ice was more effectively mitigated from pyrgeometers than pyranometers. Many systems housing either type of radiometer were $90 \%$ effective or better, including some that did not use external heat. Even systems without external heating elements were observed to have radiometer domes that were warmer than ambient air by 0.5 to $0.6^{\circ} \mathrm{C}$, which is sufficient to subsaturate the air (with respect to ice) during typical icing conditions, explaining the skillful performance. Through field and post-campaign laboratory tests, the source of this heating was found to have approximately equal contributions from waste heat from the $(\sim 10 \mathrm{~W})$ ventilator fan and adiabatic heating from compression of the air downstream from the fan. Thus, while heating elements were found to be effective, they are not required for successful ice mitigation. Instead, an important factor for success appears to be effective circulation of air over the dome.

Generally, we did not identify significant errors caused by the ventilators, and the nighttime offsets in all systems were small, consistent with Michalsky et al. (2017). One exception was heated ventilators that were susceptible to clogging by snow. These were observed to have small nighttime offsets correlated with wind velocity but not net longwave, the latter being expected for errors from infrared loss (Dutton et al., 2001). Instead, we postulate that blowing snow clogged the ventilators, reducing aspiration and causing differential heating of the radiometer after which during calm winds the heated ventilator unclogged the inlet.

When ice was present on sensors, the instantaneous biases varied but could be large, up to $+60 \mathrm{~W} \mathrm{~m}^{-2}$ in the LWD and from -211 to $+188 \mathrm{~W} \mathrm{~m}^{-2}$ in SWD. However, the monthly mean biases from ice were found to be similar to or smaller than uncertainties from other sources, which is approximately $3 \mathrm{~W} \mathrm{~m}^{-2}$ (LWD) and $2 \%$ (SWD). There are a few reasons for this unexpected result. First, the fact that icing conditions were not present continuously was a factor: from November through April, icing conditions occurred $63 \%$ of the time. The skillful performance of the ventilators was also a notable contributing factor in reducing the bias, but there were other factors as well. For SWD, compensation between positive and negative biases provided some cancellation in the monthly mean. The positive biases were tied to 
scattering of the direct beam when pyranometer domes had a cap of ice at the dome top at low sun angles during clear skies. Negative biases caused by attenuation when domes were completely encased in ice were less common. While negative biases appear to dominate during diffuse (cloudy) conditions, the irradiance is also lower at those times, which reduces the bias. Overall, positive biases were found to dominate for SWD, and the cancellation did not explain the relatively small monthly mean errors. Instead, it is the timing of the occurrence of icing that likely explains the result: biases in SWD in the monthly mean were only found in spring when both sufficient sunlight and sufficiently frequent icing conditions co-occurred. Icing in spring is commonly in the form of diurnal (morning) frost, which occurs during relatively low-light times of the day; i.e., the icing is most severe when the irradiance is small. Therefore, we recommend scheduling daily maintenance in the early morning during spring for efficiency. Indeed, icing was most severe during the polar night (November-January) when the net radiation is dominated by the longwave and pyranometers do not measure any signal. It is thus fortuitous that pyrgeometers were kept ice-free more effectively than pyranometers; i.e., small monthly mean icing biases can partially be attributed to the fact the when icing is most severe, radiometric measurements rely on a type of sensor that is more easily kept free of ice. LWD biases from ice were large when the sky was clear but reduced to near-zero in overcast conditions. Thus, the fact that the frequency of cloud occurrence is near $80 \%$ in the annual mean at Utqiagivik (Shupe et al., 2011) contributed to reducing LWD biases. This was also a mitigating factor for the SWD because the largest biases were observed near solar noon on clear days. Since cloud amount, icing meteorology, and available sunlight are all important, geographical location is meaningful and the results presented here may not be representative of other Arctic locations. We hypothesize that this may also be true for locations in the vicinity of Utqiagivik, such as over the sea ice where local or mesoscale natural de-icing mechanisms (such as downslope wind events) may be more limited.

Consistent with earlier studies reporting difficulty in distinguishing iced data in post-processing (Lanconelli et al., 2011; Matsui et al., 2012), we find that quality control procedures are poorly suited for detection of iced data because the signal caused by ice is not statistically outside the range of variability in the signal caused by clouds. Therefore, common screening methods (e.g., Long and Shi, 2008) are insufficient. Some of the non-definitive tests proposed by Long and Shi that involve cross-comparison between sensors may be more likely to identify suspect data, but results are dependent on the differential icing characteristics between the sensors. Other tests have been proposed such as comparing the sign and time derivative of the difference between upward and downward LW and SW measurements (van den Broeke et al., 2004; Wang et al., 2018), though these tests rely on similar assumptions. Some studies rely on logbooks from station personnel and thresholds for relative humidity (e.g., Sedlar et al., 2011; Miller et al., 2015, 2017; Persson et al., 2018), but because of the relative infrequency of observer records (e.g., daily) and suspect reliability of RHI as a proxy for icing (Sect. 2.2), these methods also have limitations. D-ICE demonstrates success in quality control by monitoring instrumentation with cameras, but this approach is not always practical. In keeping with van den Broeke et al. (2004), we suggest that time-derivative analysis for ice detection should be further explored. For example, the variability in the iced data in the SWD case (Fig. 4b) is much slower and smoother than would be expected from clouds in a regime not dominated by the diffuse. Thus, development of new algorithms that flag iced data based on time-variant tests might be possible if the regime can be determined to be dominated by the direct beam and can be distinguished from the consequences of instruments being unlevel or expected differences between the global and SUM SWD though the day, both of which can produce structurally similar errors.

Finally, as a baseline for comparison used for analysis, a "best-estimate" data set was produced using a combination of the measurements that were ice-free. Though an unexpected outcome of D-ICE, the number of radiometers, variety of systems, and skillful performance of the systems resulted in production of a verified ice-free data set that is nearly $100 \%$ complete for the duration of the campaign. Empirically based uncertainties were also calculated from the variability amongst the ice-free observations. This data set is uniquely well-characterized in the Arctic and therefore may be suitable for use beyond inquiry related to ice mitigation. For example, D-ICE took place during the Year of Polar Prediction (YOPP) at one of the YOPP "supersite" observatories and the campaign spanned the first wintertime YOPP Special Observing Period (SOP1) during February and March 2018. We therefore propose that the D-ICE best-estimate data products (Cox, 2020b) may be useful for model evaluations, such as the planned YOPP site Model Intercomparison Project (YOPPsiteMIP).

Code and data availability. Images collected by ARM as part of DICEXACO are available from the ARM data archive (https:// doi.org/10.5439/1507148) (Cox et al., 2019). NOAA-GML station data are available from https://www.esrl.noaa.gov/gmd/obop/ brw/ (NOAA, 2018). D-ICE data are available from NOAA-NCEI: Cox (2020a, https://accession.nodc.noaa.gov/0209059) processed radiometric data and Cox (2020b, https://accession.nodc.noaa.gov/ 0209058) best-estimate files. All D-ICE images and raw data files are available from NOAA-PSL through the D-ICE web portal, https: //www.esrl.noaa.gov/psd/arctic/d-ice/ (NOAA, 2021). QCRAD radiometric data products for OLI and NSA are available from the ARM archive at https://doi.org/10.5439/1027372 (ARM, 1996), ceilometer data at https://doi.org/10.5439/1181954 (ARM, 2010), and radiosoundings at https://doi.org/10.5439/1021460 (ARM, 1994). 
Supplement. The supplement related to this article is available online at: https://doi.org/10.5194/amt-14-1205-2021-supplement.

Author contributions. CJC and SMM designed, implemented, and led the experiment with input from TU and CNL. CJC, SMM, TU, $\mathrm{RB}, \mathrm{EH}, \mathrm{JW}, \mathrm{MK}, \mathrm{CNL}, \mathrm{AM}$, and BDT conducted the field programs. CJC led the data analysis and wrote the paper with input from all co-authors.

Competing interests. The authors declare that they have no conflict of interest.

Acknowledgements. This work is dedicated to the memory of the late Charles N. Long (formerly of CIRES) who first suggested the concept for D-ICE and provided invaluable guidance and support in developing and carrying out the experiment. We appreciate deployment assistance from John Booth (NOAA), Nicholas Lewis (Univ. Colorado), Meghan Helmberger (Univ. Colorado), Christine Schultz (NOAA), Andrew Clarke (NOAA), Amanda Looze (NOAA Pathways intern), and Kevin Olivas (NOAA summer intern); field support from David Oaks (Fairweather LLC), Ben Bishop (Sandia), and Walter Brower (UIC Science, retired); engineering and equipment support from Robert Albee (formerly STC); logistical support from Brian Vasel (NOAA), Jim Mather (PNNL), Mark Ivey (Sandia), Fred Helsel (Sandia), and Martin Stuefer (Univ. Alaska, Fairbanks); useful conversations with Robert Zamora (NOAA, retired), who assisted with adiabatic heating calculations; Ola Persson (CIRES), who suggested that natural de-icing processes vary geographically; Gert König-Langlo (AWI, retired), Jackson Osborn (CIRES), and Matthew Shupe (CIRES); Matthew Martinsen (NOAA), who provided science and logistical guidance; Richard Lataitis (NOAA), who provided an internal review; constructive comments from three anonymous reviewers and facilitation by the editors at AMT; and guidance from members of BSRN's Cold Climates Issues Working Group (CCIWG). The following organizations (points of contact) contributed equipment to the campaign: Delta-T (Dick Jenkins), Kipp \& Zonen (Victor Cassella), Hukseflux (Jörgen Konings), Eppley (Tom Kirk), EKO (William Beuttell), PMOD/WRC (Julian Gröbner), Environment and Climate Change Canada (ECCC, Andrew Platt), NOAA, MeteoSwiss (Laurent Vuilleumier), NCAR (Steven Oncley, Steven Semmer, Kurt Knudson), and the Alfred Wegener Institute (Holger Schmithüsen, Bernd Loose). Campaign logistical support was provided by the NOAA Global Monitoring Laboratory (GML). The views expressed in the article do not necessarily represent the views of the DoE or the US Government.

Financial support. This research was supported by the NOAA Arctic Research Program, the NOAA Physical Sciences Laboratory (PSL), the DoE Atmospheric Systems Research (ASR) program (grant nos. DE-SC0013306 and DE-AC36-08GO283), and the DoE Office of Energy Efficiency and Renewable Energy Solar Energy Technologies Office. This work was authored in part by the National Renewable Energy Laboratory, operated by Alliance for Sustainable
Energy, LLC, for the US Department of Energy (DOE) under contract no. DE-AC36-08GO28308.

Review statement. This paper was edited by Manfred Wendisch and reviewed by three anonymous referees.

\section{References}

Alados-Arboledas, L., Vida, J., and Jiménez, J. I.: Effects of solar radiation on performance of pyrgeometers with silicon domes, J. Atmos. Ocean. Tech., 5, 666-670, https://doi.org/10.1175/15200426(1988)005<0666:EOSROT>2.0.CO;2, 1988.

Albrecht, B. and Cox, S. K.: Procedures for improving pyrgeometer performance, J. Appl. Meteorol., $\quad 16, \quad 188-197, \quad$ https://doi.org/10.1175/15200450(1977)016<0190:PFIPP>2.0.CO;2, 1977.

Atmospheric Radiation Measurement (ARM) user facility: Balloon-Borne Sounding System (SONDEWNPN), 1/23/2018, North Slope Alaska (NSA) Central Facility, Barrow AK (C1), compiled by: Keeler, E., Ritsche, M., Coulter, R., Kyrouac, J., and Holdridge, D., ARM Data Center, https://doi.org/10.5439/1021460, updated hourly, 1994.

Atmospheric Radiation Measurement (ARM) user facility: Data Quality Assessment for ARM Radiation Data (QCRAD1LONG), 8/1/2017 to 8/1/2018, North Slope Alaska (NSA) Central Facility, Barrow AK (C1), compiled by: Riihimaki, L., Shi, Y., Zhang, D., and Long, C., ARM Data Center, https://doi.org/10.5439/1027372, updated hourly. 1996.

Atmospheric Radiation Measurement (ARM) user facility: Ceilometer (CEIL), 1/23/2018, North Slope Alaska (NSA) Central Facility, Barrow AK (C1), compiled by: Morris, V., ARM Data Center, https://doi.org/10.5439/1181954, updated hourly, 2010.

BSRN: Report of the 12th Baseline Surface Radiation Network (BSRN) Scientific Review and Workshop, 1-3 August 2012, Alfred Wegener Institute, Potsdam, Germany, WCRP Report No. 20/2012, available at: https://www.wcrp-climate.org/documents/ bsrn-12_report.pdf (last access: 4 February 2021), 2012.

BSRN: 14th Baseline Surface Radiation Network (BSRN) Scientific Review and Workshop, 26-29 April 2016, Australian Bureau of Meteorology, Canberra, Australia, WCRP Report No. 17/2016, available at: https: //www.wcrp-climate.org/WCRP-publications/2016/WCRP_ Report_17_2016_14th_BSRN_Meeting_Report.pdf (last access: 4 February 2021), 2016.

Cox, C.: De-Icing Comparison Experiment (D-ICE) campaign data: Radiometric and icing condition observations from the NOAA Barrow Atmospheric Baseline Observatory, August 2017-July 2018 (NCEI Accession 0209059), NOAA National Centers for Environmental Information, Dataset, available at: https://accession.nodc.noaa.gov/0209059 (last access: 4 February 2021), 2020a.

Cox, C.: De-Icing Comparison Experiment (D-ICE) campaign data: Best-estimate downwelling longwave and shortwave radiometric fluxes from the NOAA Barrow Atmospheric Baseline Observatory, August 2017-July 2018 (NCEI Accession 0209058), NOAA National Centers for Environmental Infor- 
mation, Dataset, available at: https://accession.nodc.noaa.gov/ 0209058 (last access: 4 February 2021), 2020b.

Cox, C. J., Walden, V. P., and Rowe, P. M.: A comparison of the atmospheric conditions at Eureka, Canada, and Barrow, Alaska (2006-2008), J. Geophys. Res., 117, D12204, https://doi.org/10.1029/2011JD017164, 2012.

Cox, C. J., Walden, V. P., Rowe, P. M., and Shupe, M. D.: Humidity trends imply increased sensitivity to clouds in a warming Arctic, Nat. Commun., 6, 10117, https://doi.org/10.1038/ncomms10117, 2015.

Cox, C. J., Stone, R. S., Douglas, D. C., Stanitski, D. M., Divoky, G. J., Dutton, G. S., Sweeney, C., George, J. Craig, and Longenecker, D.: Drivers and environmental responses to the changing annual snow cycle of northern Alaska, B. Amer. Meteorol. Soc., 98, 2559-2577, https://doi.org/10.1175/BAMS-D-160201.1, 2017.

Cox, C. J., Morris, S. M., Uttal, T., Long, C. N., and McComiskey, A.: The De-Icing Comparison Experiment - ARM Contribution (DICEXACO) Field Campaign Report, edited by: Stafford, R., ARM user facility, DOE/SC-ARM-19-020, https://doi.org/10.5439/1507148, 2019.

Driemel, A., Augustine, J., Behrens, K., Colle, S., Cox, C., CuevasAgulló, E., Denn, F. M., Duprat, T., Fukuda, M., Grobe, H., Haeffelin, M., Hodges, G., Hyett, N., Ijima, O., Kallis, A., Knap, W., Kustov, V., Long, C. N., Longenecker, D., Lupi, A., Maturilli, M., Mimouni, M., Ntsangwane, L., Ogihara, H., Olano, X., Olefs, M., Omori, M., Passamani, L., Pereira, E. B., Schmithüsen, H., Schumacher, S., Sieger, R., Tamlyn, J., Vogt, R., Vuilleumier, L., Xia, X., Ohmura, A., and König-Langlo, G.: Baseline Surface Radiation Network (BSRN): structure and data description (1992-2017), Earth Syst. Sci. Data, 10, 1491-1501, https://doi.org/10.5194/essd-10-1491-2018, 2018.

Dutton, E. G., Michalsky, J. J., Stoffel, T., Forgan, B. W., Hickey, J., Nelson, D. W., Alberta, T. L., and Reda, I.: Measurement of broadband diffuse solar irradiance using current commercial instrumentation with a correction for thermal offset errors, J. Atmos. Ocean. Tech., 18, 297-314, https://doi.org/10.1175/15200426(2001)018<0297:MOBDSI>2.0.CO;2, 2001.

Gröbner, J., Reda, I., Wacker, S., Nyeki, S., Behrens, K., and Gorman, J.: A new absolute reference for atmospheric longwave irradiance measurements with traceability to SI units, J. Geophys. Res., 119, 7083-7090, https://doi.org/10.1002/2014JD021630, 2014.

Kandula, M.: Frost growth and densification in laminar flow over flat surfaces, Int. J. Heat Mass. Trans., 54, 3719-3731, https://doi.org/10.1016/j.ijheatmasstransfer.2011.02.056, 2011.

Koerner, R. M., Gill, A., Apollonio, S., Greenhouse, J. P., and Hyndman, R. D.: The Devon Island Expedition 1960-64, Arctic, 16, 57-76, https://doi.org/10.14430/arctic3523, 1963.

Lanconelli, C., Busetto, M., Dutton, E. G., König-Langlo, G., Maturilli, M., Sieger, R., Vitale, V., and Yamanouchi, T.: Polar baseline surface radiation measurements during the International Polar Year 2007-2009, Earth Syst. Sci. Data, 3, 1-8, https://doi.org/10.5194/essd-3-1-2011, 2011.

Lenschow, D. H.: The measurement of air velocity and temperature using the NCAR Buffalo Aircraft Measurement System, National Center for Atmospheric Research, NCARTN/EDD-74, University Corporation for Atmospheric Research, https://doi.org/10.5065/D6C8277W, 1972.
Long, C. N. and Shi, Y.: An automated quality assessment and control algorithm for surface radiation measurements, Open Atmos. Sci. J., 2, 23-37, https://doi.org/10.2174/1874282300802010023, 2008.

Marty, C., Philipona, R., Delamere, J., Dutton, E. G., Michalsky, J., Stamnes, K., Storvold, R., Stoffel, T., Clough, S. A., and Mlawer, E. J.: Downward longwave irradiance uncertainty under arctic atmospheres: Measurements and modeling, J. Geophys. Res., 108, 4358, https://doi.org/10.1029/2002JD002937, 2003.

Matsui, N., Long, C. N., Augustine, J., Halliwell, D., Uttal, T., Longenecker, D., Niebergall, O., Wendell, J., and Albee, R.: Evaluation of Arctic broadband surface radiation measurements, Atmos. Meas. Tech., 5, 429-438, https://doi.org/10.5194/amt-5429-2012, 2012.

McArthur, B.: World Climate Research Programme Baseline Surface Radiation Network (BSRN) Operations Manual Version 2.1, WCRP-121 WMO/TD-No. 1274, 176 pp., available at: https://bsrn.awi.de/fileadmin/user_upload/bsrn.awi.de/ Publications/McArthur.pdf (last access: 4 February 2021), 2005.

Michalsky, J. J., Harrison, L. C., and Berkheiser III, W. E.: Cosine response characteristics of some radiometric and photometric sensors, Sol. Energy, 54, 397-402, https://doi.org/10.1016/0038092X(95)00017-L, 1995.

Michalsky, J. J., Kutchenreiter, M., and Long, C. N.: Significant improvements in pyranometer nighttime offsets using highflow DC ventilation, J. Atmos. Ocean. Tech., 34, 1323-1332, https://doi.org/10.1175/JTECH-D-16-0224.1, 2017.

Miller, N. B., Shupe, M. D., Cox, C. J., Walden, V. P., Turner, D. D., and Steffen, K.: Cloud radiative forcing at Summit, Greenland, J. Climate, 28, 6267-6280, https://doi.org/10.1175/JCLI-D-150076.1, 2015.

Miller, N. B., Shupe, M. D., Cox, C. J., Noone, D., Persson, P. O. G., and Steffen, K.: Surface energy budget responses to radiative forcing at Summit, Greenland, The Cryosphere, 11, 497516, https://doi.org/10.5194/tc-11-497-2017, 2017.

National Oceanic and Atmospheric Administration (NOAA): Meteorology measurements from the NOAA/GML Barrow Baseline Observatory, available at: https://www.esrl.noaa.gov/gmd/obop/ brw/, last access: 6 March 2018.

National Oceanic and Atmospheric Administration (NOAA): DICE De-Icing Comparison Experiment, available at: https: //www.esrl.noaa.gov/psd/arctic/d-ice/, last access: 4 February 2021.

Ohmura, A., Dutton, E. G., Forgan, B., Flöhlich, C., Gilgen, H., Hegner, H., Heimo, A., König-Langlo, G., McArthur, B., Müller, G., Philipona, R., Pinker, R., Whitlock, C. H., Dehne, K., and Wild, M.: Baseline Surface Radiation Network (BSRN/WCRP): New precision radiometery for climate research, B. Amer. Meteorol. Soc., 79, 2115-2136, https://doi.org/10.1175/15200477(1998)079<2115:BSRNBW>2.0.CO;2, 1998.

Overland, J. E. and Wang, M.: Arctic-midlatitude weather linkages in North America, Polar Sci., 16, 1-9, https://doi.org/10.1016/j.polar.2018.02.001, 2018.

Persson, P. O. G. and Semmer, S.: Impacts of Riming on Arctic Surface Energy Budget Measurements, Autonomous Polar Observing Systems Workshop (https://www.iris.edu/hq/polar_ workshop2010/, last access: 12 February 2021), Potomac, MD, 30 September-1 October 2010 (poster accessed through personal communication with P. O. G. Persson, 29 August 2016). 
Persson, P. O. G., Blomquist, B., Guest, P., Stammerjohn, S., Fairall, C. W., Rainville, L., Lund, B., Ackley, S., and Thomson, J.: Shipboard observations of meteorology and near-surface environment during autumn freezeup in the Beaufort/Chukchi Seas, J. Geophys. Res., 123, 4930-4969, https://doi.org/10.1029/2018JC013786, 2018.

Sedlar, J., Tjernström, M., Mauritsen, T., Shupe, M. D., Brooks, I. M., Persson, P. O. G., Birch, C. E., Leck, C., Sirevaag, A., and Nicolaus, M.: A transitioning Arctic surface energy budget: the impacts of solar zenith angle, surface albedo and cloud radiative forcing, Clim. Dynam., 37, 1643-1660, https://doi.org/10.1007/s00382-010-0937-5, 2011.

Shupe, M. D., Walden V. P., Eloranta, E., Uttal, T., Campbell, J. R., Starkweather, S. M., and Shiobara, M.: Clouds at Arctic atmospheric observatories. Part I: Occurrence and macrophysical properties, J. Appl. Meteorol. Clim., 50, 626-644, https://doi.org/10.1175/2010JAMC2467.1, 2011.

Stuefer, M., Cassella, V., Korevaar, M., and Wong, T.: Heater Pyrheliometer Field Campaign Report, edited by: Stafford, R., ARM user facility, DOE/SC-ARM-19-030, 2019.

Thompson, D. C.: Aerodynamic heating of miniature bead thermistor thermometers in a rarified airstream, J. Appl. Meteorol., 7, 504-508, https://doi.org/10.1175/15200450(1968)007<0504:AHOMBT>2.0.CO;2, 1968. van den Broeke, M., van As, D., Reijmer, C., and van de Wal, R.: Assessing and improving the quality of unattended radiation measurements in Antarctica, J. Atmos. Ocean. Tech., 21, 1417-1431, https://doi.org/10.1175/15200426(2004)021<1417:AAITQO>2.0.CO;2, 2004.

Wang, W., Zender, C. S., and van As, D.: Temporal characteristics of cloud radiative effects on the Greenland ice sheet: discoveries from multiyear automatic weather station measurements, J. Geophys. Res., 123, 11348-11361, https://doi.org/10.1029/2018JD028540, 2018.

Weisser, U.: Status update of BSRN station Sonnblick (SON) - (Apr 2016), 14th VSRN Science Review and Workshop, Canberra, Australia, 26-29 April 2016, available at: https://www.esrl.noaa.gov/gmd/grad/meetings/BSRN_talks/ P1_7_Poster_BSRN_Canberra_Olefs_Weiser_2016.pdf (last access: 4 February 2021), 2016.

Wendler, G., Moore, B., and Galloway, K.: Strong temperature increase and shrinking sea ice in Arctic Alaska, Open Atmos. Sci. J., 8, 7-15, https://doi.org/10.2174/1874282301408010007, 2014. 